\title{
Effect of Die Head Temperature at Compounding Stage on the Degradation of Linear Low Density Polyethylene/Plastic Film Waste Blends after Accelerated Weathering
}

\author{
S. M. Al-Salem, ${ }^{1}$ N. M. Al-Dousari, ${ }^{1}$ G. Joseph Abraham, ${ }^{2}$ \\ M. Aromin D'Souza, ${ }^{1}$ O. A. Al-Qabandi, ${ }^{3}$ and W. Al-Zakri ${ }^{1}$ \\ ${ }^{1}$ Environment \& Life Sciences Research Centre, Kuwait Institute for Scientific Research, P.O. Box 24885, 13109 Safat, Kuwait \\ ${ }^{2}$ Petroleum Research Centre, Kuwait Institute for Scientific Research, P.O. Box 24885, 13109 Safat, Kuwait \\ ${ }^{3}$ ReD Department, EQUATE Petrochemical Company, P.O. Box 91717, 61008 Ahmadi, Kuwait
}

Correspondence should be addressed to S. M. Al-Salem; ssalem@kisr.edu.kw

Received 20 July 2016; Accepted 12 October 2016

Academic Editor: Domenico Acierno

Copyright $\odot 2016$ S. M. Al-Salem et al. This is an open access article distributed under the Creative Commons Attribution License, which permits unrestricted use, distribution, and reproduction in any medium, provided the original work is properly cited.

\begin{abstract}
Accelerated weathering test was performed on blends of linear low density polyethylene (LLDPE) and plastic film waste constituting the following percentages of polyolefin polymers (wt.\%): LLDPE (46\%), low density polyethylene (LDPE, 51\%), high density polyethylene (HDPE, 1\%), and polypropylene (PP, $2 \%$ ). Compounded blends were evaluated for their mechanical and physical (optical) properties. The impact of photodegradation on the formulated blends was studied, and loss of mechanical integrity was apparent with respect to both the exposure duration to weathering and waste content. The effect of processing conditions, namely, the die head temperature (DHT) of the blown-film assembly used, was investigated in this work. It was witnessed that surpassing the melting point of the blends constituting polymers did not always result in a synergistic behaviour between polymers. This was suspected to be due to the loss of amorphous region that polyolefin polymers get subjected to with UV exposure under weathering conditions and the effect of the plastic waste constituents. The total change in colour $(\Delta E)$ did not change with respect to DHT or waste content due to rapid change degradation on the material's surface. Haze (\%) and light transmission (\%) decreased with the increase in waste content which was attributed to lack of miscibility between constituting polymers.
\end{abstract}

\section{Introduction}

Weathering tests are typically performed to investigate the durability and integrity of polymers and have been extensively reported in the past for various polyolefins to study their degradation [1-4]. However, the behaviour and properties of materials after weathering are not always predictable and can always give way to tailor and engineer products depending on the applications intended. This is due to the different levels of heat, UV intensity, and climatic and metrological conditions polymers get subjected to, which causes severe crosslinking, loss of amorphous regions, and morphological changes in the polymer's structure with time [5]. Recently, attention is paid to polymer weathering studies of blends to determine their optimal use and report of change in properties is always linked with the type of constituting polymers and the degrading environment they are subjected to $[6,7]$. In addition, polyolefins are the main polymer converted for consumer products in various dayto-day applications, considered to be also the governing commodity in the petrochemicals market. Literature is also scant in degradation studies of polyolefin polymers blends after weathering tests, which is an active area of research since plastic products typically consist of a blend of polymers.

Moreover, past reports show that polyethylene (PE) is typically the governing polymer of the properties of polyolefin blends $[2,8-11]$. This is due to the fact that it has a relatively lower melting point $\left(T_{m}\right)$ than other common polyolefins (i.e., polypropylene, PP) which alters the studied blend's miscibility $[5,11]$. Moreover, linear low density polyethylene (LLDPE) is typically converted for packaging and agriculture applications and ends up along with other PE types in large 
quantities in the plastic solid waste (PSW) streams over the world [12-14]. PE is also immensely susceptible to UV radiation and climatic conditions $[15,16]$, and the study of its degradation in blends is of paramount importance to determine its optimal use in various applications. Dilara and Briassoulis [17] described the mechanisms involved in PE degradation and pointed out that free radicals produced during photodegradation lead to an extensive degradation, loss of mechanical properties, and an alteration in physical ones due to surface changes. This was also supported by Andrady et al. [18] work on polyolefin polymers weathering. LDPE films were extruded and blown in Tuasikal et al. [19] work and were exposed to accelerated weathering tests to investigate the effect of various stabilizers added to the blends. A clear exponential reduction was reported in the mechanical properties which was also dependent on the materials thickness and the formulated blends characteristics. Al-Salem [20] reported the mechanical and physical properties of thin LLDPE films exposed to accelerated and natural weathering after exposure to different durations. It was observed that the surface changes due to suspected photooxidation and alteration in the semicrystalline structure of PE lead to a rapid deterioration of the film samples compared to past research utilizing similar blends.

Typically, polymers undergoing mechanical processing are deteriorated due to heat cycle exposure during plastic product conversion and processing [21]. The accumulation of polymer waste is in need of intervention by studying routes of mechanical and chemical treatment [22]. Hence, to valorise PE and to study blends constituting polyolefins can be of immense environmental benefit in reducing PSW accumulation by tailoring products from blends of waste origin. This can lead to engineering products with desired mechanical and physical properties that are acceptable to market standards and can be reintroduced in the industrial loop of plastic conversion with minimal costs [17, 23, 24]. In addition, to determine the optimal processing conditions by altering the conversion process parameters, the extent of properties loss and materials degradation can be determined and reduction of energy requirements can be achieved. In this work, the degradation effect on virgin LLDPE and virgin LLDPE blends with PSW originating from plastic waste films is reported. The blends were formulated under three different Die Head Temperatures (DHTs) at compounding stage of the blends and the effect of processing conditions is studied. This is aimed at determining the change in properties the processing conditions cause. The mechanical (i.e., Young's modulus, stress, strain, and force at rupture) and physical properties (i.e., haze, light transmission, and total change in colour) of the studied specimens are reported. The reported results in this paper can lead to various opportunities for valorising dry blends originating from waste. Such work can also lead to the reduction of direct environmental burdens associated with plastic product conversion and PSW accumulation.

\section{Experimental}

2.1. Materials and Random Sampling. Plastic film waste (200 kg commingled films) was secured from the National
Waste Management Company (NWM Co., Kuwait). The films supplied were exposed to different durations of sunlight, up to 3 months, during their storage in the company's yard rendering them as an exposed municipal waste material. To investigate the polymer types constituting the plastic film waste that is typically present in the Kuwaiti MSW stream, the melting point $\left(T_{m}\right)$ of the samples was determined. The films were secured in 15 batches, and 10 random samples were chosen from each plastic film batch in accordance with ASTM D 1898-68 [25]. The samples were tested for $T_{m}$ using a TA instrument Q-series model differential scanning calorimeter (DSC). A $9 \pm 0.1 \mathrm{mg}$ sample was placed in the DSC crucible and equilibrated at $40^{\circ} \mathrm{C}$ for $5 \mathrm{~min}$, after which the sample was heated using a $10^{\circ} \mathrm{C} \mathrm{m^{-1 }}$ ramp to $200^{\circ} \mathrm{C}$; standard practices and current laboratory protocols for polymer thermal analysis were followed [26]. The waste material constituted the following percentages of the polymers after laboratory analysis was achieved (wt\%): LLDPE (46\%), LDPE (51\%), HDPE (1\%), and PP (2\%). More details are to be found elsewhere [27-29].

2.2. Samples Compounding. The waste films were milled to $3 \times 3 \mathrm{~mm}$ flakes using a Tecnova cutting mill and pelletized to $3 \mathrm{~mm}$ pellets using a Tecnova industrial single screw extruder $(L / D=30)$ at a pressure of 40 bar and 70 RPM. The cooling water temperature was maintained between 16 and $17^{\circ} \mathrm{C}$. LLDPE was graciously supplied by the EQUATE Petrochemical Company (Kuwait) and used in this work as white translucent pellets with a density of $0.918 \mathrm{~g} / \mathrm{cm}^{3}$ and a melt flow index (MFI) of $2 \mathrm{~g} / 10 \mathrm{~min}$. For the purpose of confidentiality, the company did not provide details of the additives in this commercial grade. Virgin and waste polymers were weighed, extruded, and blown using a single screw extruder (Tecnova, $L / D=30,45$ bar and $85 \mathrm{RPM}$ ) and a film blowing machine (Kung Hsing monolayer) with a water cooling temperature maintained between 16 and $17^{\circ} \mathrm{C}$ (Figure 1). Three Die Head Temperatures (DHTs) in the extruder section were used for three different batches of the produced film products. The first was $175^{\circ} \mathrm{C}$, and the second and third were 185 and $195^{\circ} \mathrm{C}$. All DHT surpassed $T_{m}$ of all the polymers, but the severity of the plastic grade processing was varied by changing the DHT from the recommended temperature provided by the supplier (i.e., $175^{\circ} \mathrm{C}$ ) to examine the effects on measured properties. The six zones of the extruder were maintained in a temperature range of 175$185^{\circ} \mathrm{C}[26,30,31]$.

The weight ratios of virgin LLDPE to waste were 100/0, 90/10, 75/25, 50/50, 75/25, and 10/90. Throughout the rest of this paper, these will be coded as follows: V, B1, B2, B3, B4, and B5. The extruded sheets of $100 \mu \mathrm{m}$ thickness were cut using a standard cutting die (Ray Ran UK cutting press, model RR/PCP) to produce $20 \times 1 \mathrm{~cm}$ films for further characterization. This thickness was chosen as it was considered a good representation of the various applications of plastic films in indoor or outdoor uses. The samples appeared consistent with no visible fractures or crazing and were comparable to each other by touch. Furthermore, the addition of the waste material to the virgin polymer was observed to result in a more yellow colouration as a result of 


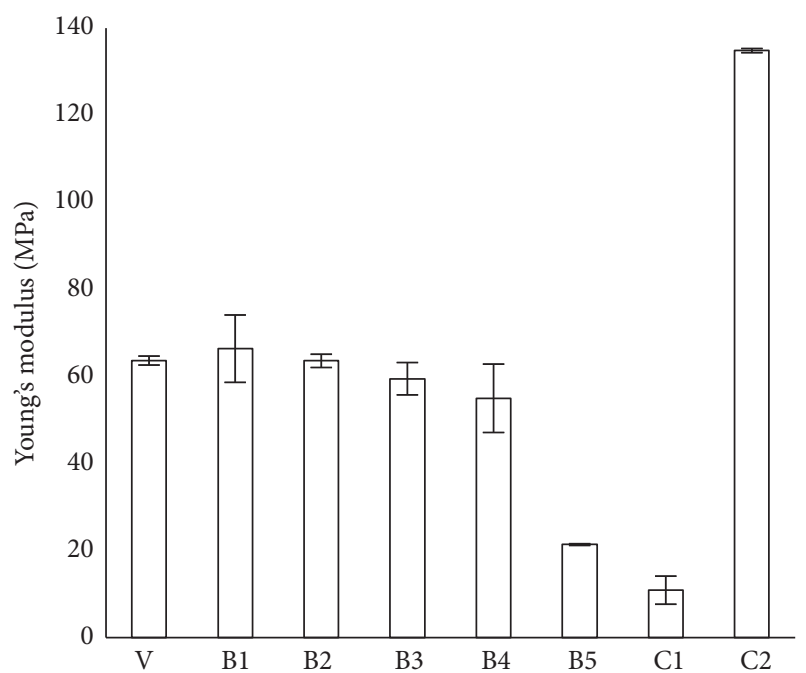

(a)

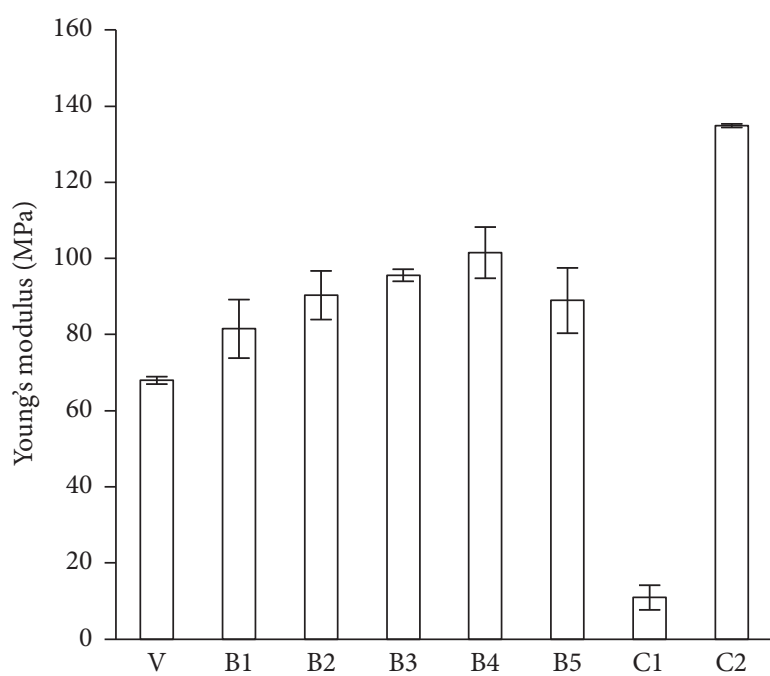

(b)

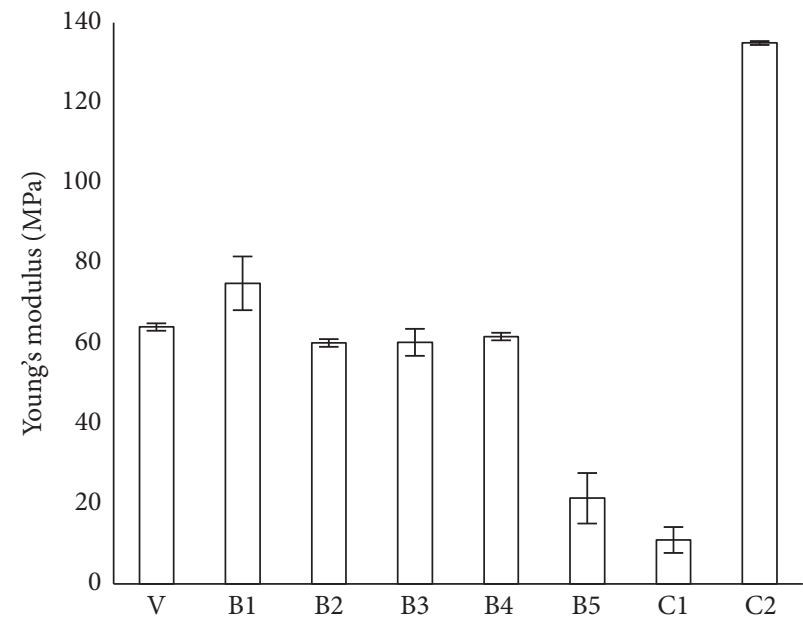

(c)

FIGURE 1: Young's modulus (MPa) measured for the studied materials in comparison to the commercial grade products. Die Head Temperature $(\mathrm{DHT})=(\mathrm{a}) 175^{\circ} \mathrm{C}$, (b) $185^{\circ} \mathrm{C}$ and (c) $195^{\circ} \mathrm{C}$.

the loss of transparency in comparison with virgin specimens [30]. All samples were stored under laboratory conditions of $23^{\circ} \mathrm{C} / 50 \%$ relative humidity and kept in the dark between sample formulation and testing.

2.3. Accelerated Weathering. Films of the different virgin/waste blend formulations were exposed to controlled laboratory accelerated weathering (ageing) in accordance with ASTM 4329 [32] to examine their applicability for outdoor applications. Samples were mounted on racks facing UV lamps with no empty spaces in the panels in order to maintain repeatable testing conditions. Cycle A procedure was used for general applications, that is, $8 \mathrm{~h}$ of UV exposure at $60^{\circ} \mathrm{C}$ followed by $4 \mathrm{~h}$ of condensation at $50^{\circ} \mathrm{C}$. At the end of each continuous weathering test, the chamber was cooled to room temperature, and trays were set to rest on a flat surface for a minimum of $24 \mathrm{~h}$. Samples were set to rest for a minimum of $72 \mathrm{~h}$ before characterization following the methodology of Johnson et al. [33].
2.4. Mechanical Properties. After the accelerated weathering, the blends were evaluated for mechanical (tensile) properties with experiments conducted at room temperature to study the impact of the weathering. Mechanical properties were evaluated in accordance with ASTM D882 [27]. Experiments were conducted using a Testometric (UK) universal testing machine model DBBMTCL-250 kg (M250-2.5 kN load cell) with a $500 \mathrm{~mm} / \mathrm{min}$ speed. The measured properties include Young's modulus $(\mathrm{MPa})$, the stress at break $(\mathrm{MPa})$, and the strain at rupture (\%). The measurement values obtained came from the average of 5 replicate specimens stored in the machine's software $[26,30,31]$.

2.5. Physical (Optical) Properties. A MF709 (spherical) haze meter (model BS 2782) was used to measure the haze and light transmission at the midpoint of the studied samples, in accordance with ASTM D1003 [28] and as following past works [26, 29-31]. Replicates of the specimens were tested for haze (\%) and light transmission (\%) and the average of the readings 
is reported. Standard colour parameters for light/dark $\left(L_{s}^{*}\right)$, $\mathrm{red} /$ green $\left(a_{s}^{*}\right)$, and yellow/blue $\left(b_{s}^{*}\right)$ were measured using a Nippon Denshoku model NF333 colourimeter according to ASTM D2244 [34]. The measured parameters were then used to calculate the total change in colour between control samples and each weathered formulation; thus,

$$
\Delta E=\sqrt{(\Delta L)^{2}+(\Delta a)^{2}+(\Delta b)^{2}}
$$

where $\Delta L, \Delta a$, and $\Delta b$ are the values of the difference between the control specimen measurements (control samples with no exposure to weathering) and those of each tested batch. The average readings of the replicates for each formulation were measured and are reported.

\section{Results and Discussion}

3.1. Comparability with Market Products. Figure 1 shows Young's modulus of the blends formulated in this work under the three different DHTs $\left(175,185\right.$, and $\left.195^{\circ} \mathrm{C}\right)$ to two commercial grade film products (carrier bags) available on the local Kuwaiti market (i.e., C1 and C2). The two commercial products are blends of HDPE/LDPE (50/50 wt\%) converted from fresh plastic resin, which is a common practice for producing such products in Kuwait. HDPE used by local converters is typically of high load melt flow index (MFI) exceeding 10 (2.16 g/10 min) and a density $(\rho)$ of $0.952 \mathrm{~g} / \mathrm{cm}^{3}$. The LDPE typically used is of a melt flow rate (MFR) and $r$ equal to $0.3 \mathrm{~g} / 10 \mathrm{~min}$ and $0.922 \mathrm{gm} / \mathrm{cm}^{3}$, respectively. Comparatively, the first product $(\mathrm{C} 1)$ shows the lowest modulus (by more than 50\%) amongst the studied samples. The range of Young's modulus measured for the virgin LLDPE and the recycled blends (B1-B5) is 21-75 MPa. The virgin LLDPE shows a higher modulus than the product $\mathrm{C} 1$, indicating that $\mathrm{C} 1$ is more soft and deforms more rapidly when compared with $100 \%$ virgin resin. Similarly, all of the recycled blends formulated and examined in this work also show a higher modulus than $\mathrm{C} 1$, indicating more rigidity. This shows that the recycled blends exhibit higher stiffness and do not deform easily in comparison to $\mathrm{Cl}$ (Figure 2). This could also be an argument for the addition of chemical additives to decrease stiffness based on consumers satisfaction and market demands $[35,36]$. Furthermore, the recycled blends show a decreasing trend in modulus as the waste content increases in the case of samples processed at DHTs 175 and $195^{\circ} \mathrm{C}$ (Figures 2(a) and 2(c)), reaching approximately onethird of the B1 (90/10 wt\%) value when compared with B5, that is, $10 / 90$ virgin/waste blend (wt\%). This indicates that the plastic film waste acts as a deteriorating agent for the virgin LLDPE grade used. Therefore, to increase the stiffness of the material, a binding agent would be required. However, for applications such as carrier or grocery bags, the recycled blends studied surpass the measure of stiffness required for the local market and can be readily used after extrusion/blowfilming in the processing stage. This is also applicable to the high waste content blends (i.e., over $50 \mathrm{wt} \%, \mathrm{B3}, \mathrm{B} 4$, and B5), which shows a potential for utilizing the PSW in Kuwait to the benefit of the local plastic product converters. In the case of the sample processed at a DHT equal to $185^{\circ} \mathrm{C}$ (Figure 2(b)),
Young's modulus was observed to increase incrementally with the addition of waste. This indicates that under this DHT the material is not homogenised physically after solidifying from the polymer molten stage in the extrusion process. This shows that a more severe temperature is required at the die head of the extruder to homogenise the blend studied. In addition, for the B5 samples, a decline in the Young modulus value was also noted in comparison with other formulations, indicating that the virgin plastic resin (LLDPE) is not as influenced by the temperature of the die head as the other materials in the blend (Figure 2(b)).

However, the C2 product shows the highest modulus among the studied products. This could be related to the storage conditions of the product prior to use, type of the production process (i.e., extrusion and/or blown-film), and the number of heating/cooling cycles used to produce the films. This conclusion is based on the fact that both the commercial products ( $\mathrm{C} 1$ and $\mathrm{C} 2$ ) have a similar average thickness $(30 \mu \mathrm{m})$ with similar materials constituting them (1:1 ratio of HDPE/LDPE by weight). Hence, it is concluded that manufacturers follow the processing guidelines of the $\mathrm{C1}$ product producers, which will lower Young's modulus and consequently lower the processing cost due to a reduction in the number of heating cycles the plastic material undergo. The value of Young's modulus is affected by the heat treatment that the plastic undergoes, resulting in an increased stiffness at lower temperatures. Hence, by lowering the temperature of the processing cycles, the value of Young's modulus for a product will be reduced to acceptable market standards (similar to $\mathrm{C1}$ ), which will consequently reduce the costs on the $\mathrm{C} 2$ product converter. Because Young's modulus shows higher values in the case of $\mathrm{B} 1-\mathrm{B} 5$ than for $\mathrm{C} 1$, it is recommended to utilize the plastic film waste fraction generated in Kuwait as a dry filler to reduce the cost of processing virgin materials. Figure 2(c) shows Young's modulus values measured for the formulated blends using a DHT equal to $195^{\circ} \mathrm{C}$, in comparison with the examined commercial products $(\mathrm{C} 1$ and $\mathrm{C} 2$ ). A similar trend was observed in the studied samples showing higher modulus values than C1. However, B1 samples show a higher Young's modulus by approximately $10 \mathrm{MPa}$ when compared with the values obtained under a DHT of $175^{\circ} \mathrm{C}$ (Figure $2(\mathrm{a})$ ). This could be because the virgin/waste blend was made at a higher temperature in a molten state, resulting in a stiffer product when cooled. The compatibility of the samples studied, in terms of modulus, suggests a very good potential for waste utilization. If the product's stiffness is used as an indicator, a DHT of $175^{\circ} \mathrm{C}$ represents the optimal processing condition at the extruder's die to process the blend, rather than a higher one $\left(195^{\circ} \mathrm{C}\right)$. This will reduce the utility demand on the plastic product converter with no effect on the quality of the final product.

It was also noted that the blends $\mathrm{B} 2$ to $\mathrm{B} 4$ produced with a DHT equal to 175 and $195^{\circ} \mathrm{C}$ show almost equal modulus values. This indicates that the effect of the virgin material content and the temperature is notable in high-content waste fractions ( $>50 \mathrm{wt} \%$ ) when compared with the virgin LLDPE (V) or the B5 formulation. Typically, Young's modulus is not related to the waste content in the blend $[23,37,38]$, especially 


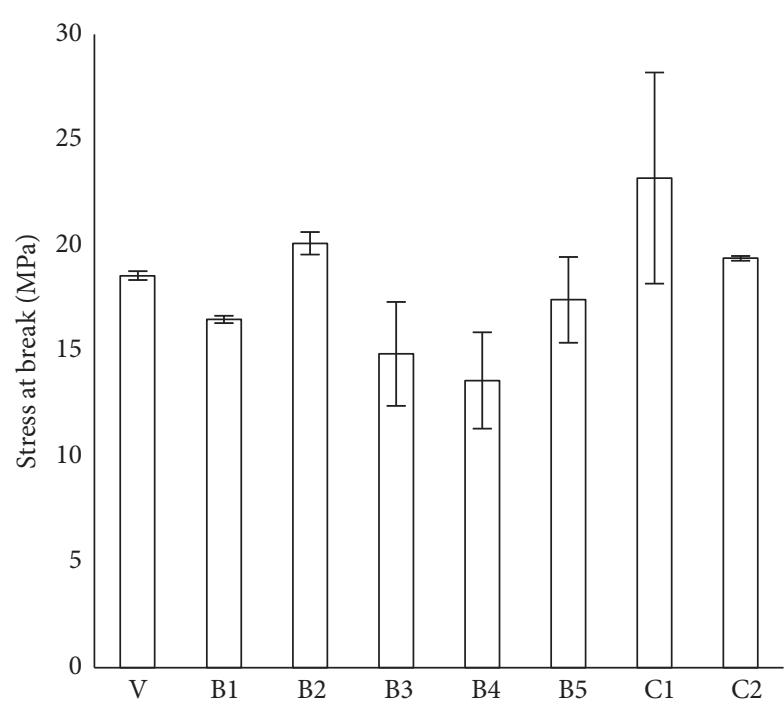

(a)

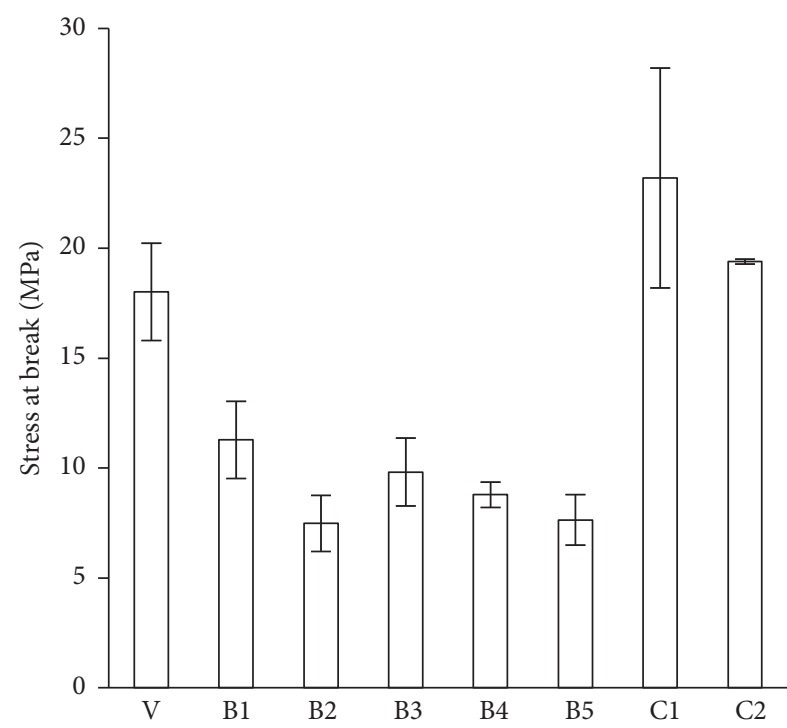

(b)

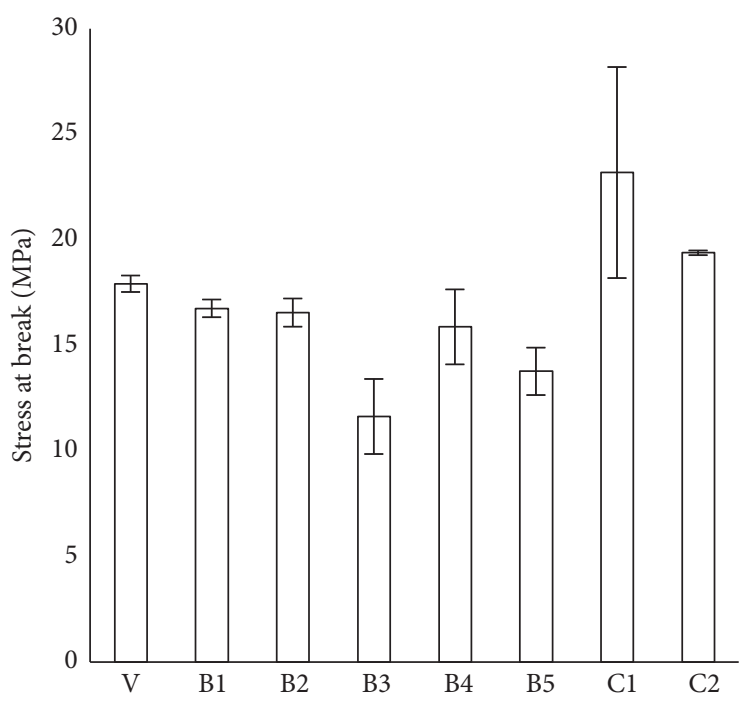

(c)

Figure 2: Stress at break (MPa) measured for the studied materials in comparison to the commercial grade products. Die Head Temperature $(\mathrm{DHT})=(\mathrm{a}) 175^{\circ} \mathrm{C},(\mathrm{b}) 185^{\circ} \mathrm{C}$, and (c) $195^{\circ} \mathrm{C}$.

when additives are employed in the processing of the plastic product. The modulus is also dependent on the individual modulus values of the materials used in the blend and exhibits an increasing trend when certain polyolefin or polyester polymers are present in the blend that is proportional to the amount [23]. The values of Young's modulus obtained in this work are also acceptable by international market standards for greenhouse plastic covers [38]. This shows a great potential for utilizing the compounding technique used in this work for the production outdoor products of plastic film waste origin.

Stress at break (MPa) was measured for the virgin LLDPE (V) and recycled blends (B1-B5) and compared with both of the commercial products $(\mathrm{Cl}$ and $\mathrm{C} 2)$, and these measurements are reported in Figure 3. The results of the samples produced under a DHT equal to $175^{\circ} \mathrm{C}$ did not show a clear trend between the amount of waste content and the value of the stress at break (MPa) (Figure 3(a)). Elzubair and Miguez Suarez [39] showed that waste content does not affect the stress values even in the presence of additives and fillers in recycled HDPE. This could be attributed to the crystallinity of the polymers constituting each blend at room temperature and the change in their amorphous region due to processing conditions, especially when considering the number of polymers each blend possesses [5, 40, 41]. This also indicates that on a molecularly level the crystallinity of the B2 formulation is higher than the other examined blends, which is due to it exhibiting a higher stress at break as observed in Figure 3(a). This could be of benefit to plastic converters in understanding the impact of stress (and other 


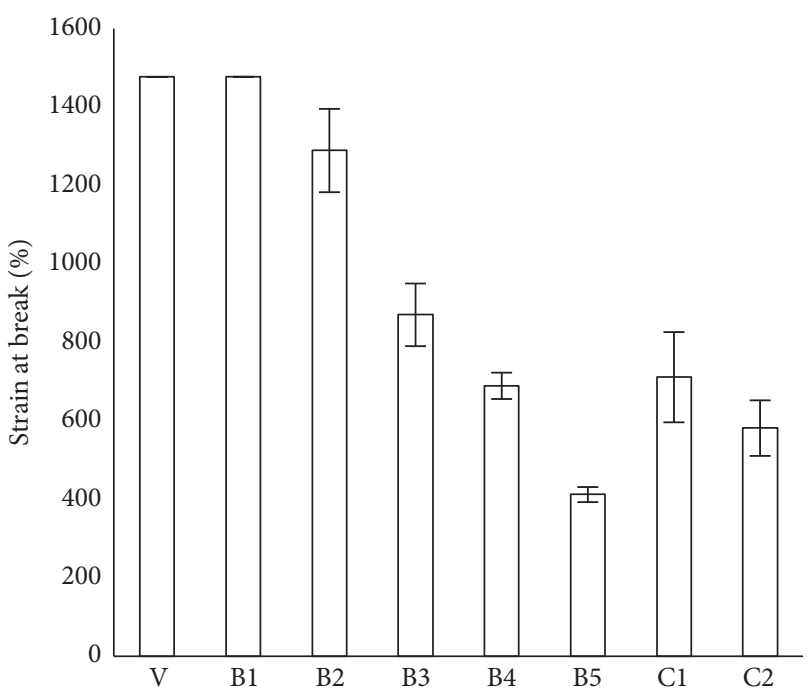

(a)

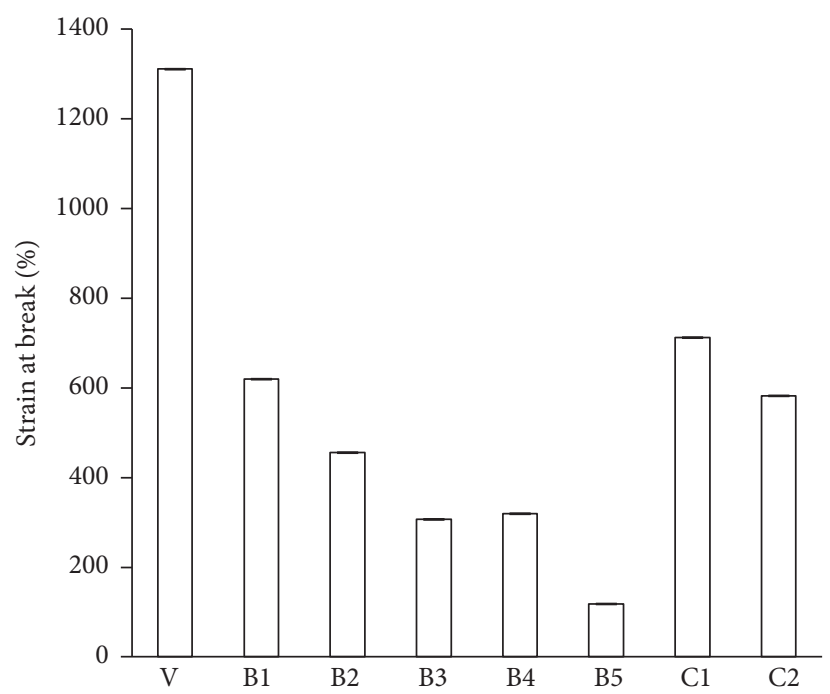

(b)

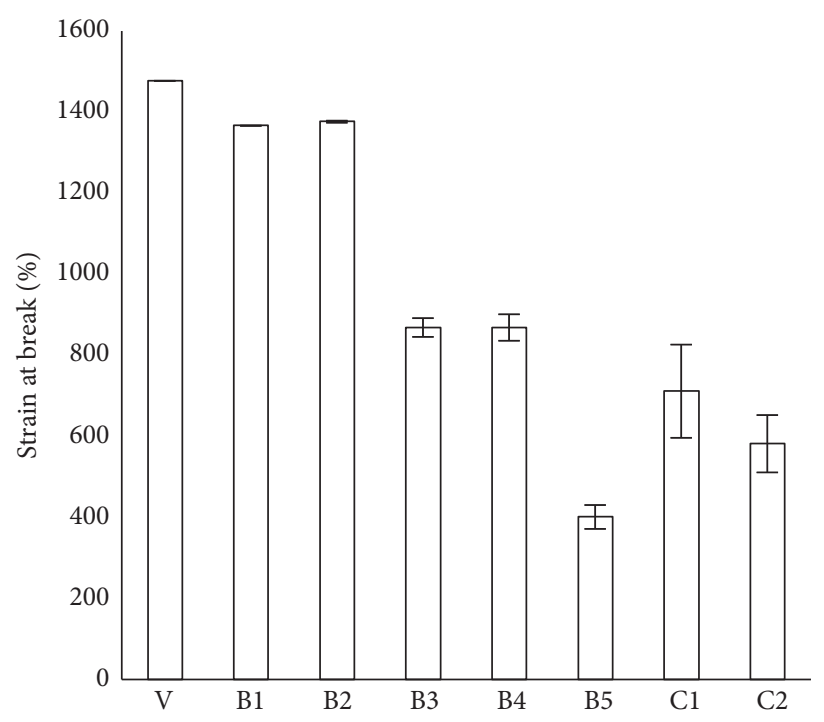

(c)

FIGURE 3: Strain at break (\%) measured for the studied materials in comparison to the commercial grade products. Die Head Temperature $(\mathrm{DHT})=(\mathrm{a}) 175^{\circ} \mathrm{C}$, (b) $185^{\circ} \mathrm{C}$, and (c) $195^{\circ} \mathrm{C}$.

mechanical properties) when such blends are employed in product development stages, considering that all recycled formulations show a comparable stress at break with the examined commercial products ( $\mathrm{C} 1$ and $\mathrm{C} 2$, Figure 3 ), with less than $5 \%$ mean deviation among the values. Figure $3(\mathrm{~b})$ shows the stress at break of the samples processed under a DHT of $185^{\circ} \mathrm{C}$. A decreasing trend of stress at break was observed with the content of waste in the studied samples. This shows that, at a DHT of $185^{\circ} \mathrm{C}$, the temperature does not result in a miscible material that can be considered as strong as a single resin one. This is unlike samples processed under a DHT equal to $175^{\circ} \mathrm{C}$ or $195^{\circ} \mathrm{C}$, where the optimal processing temperature of the virgin material $\left(175^{\circ} \mathrm{C}\right)$ and the severe DHT of $195^{\circ} \mathrm{C}$ create a material that acts as a pseudo-single polymer material that is not affected by the deteriorating agents (i.e., the waste). Figure 3(c) shows the stress at break of the samples processed under a DHT of $195^{\circ} \mathrm{C}$. In comparison with the samples processed under a DHT of $175^{\circ} \mathrm{C}$, a more significant decrease with respect to waste ratio of over $15 \%$ was observed. This could be the result of both the high temperature used and the start of the waste material diffusion into the polymer matrix of the virgin LLDPE at this temperature, resulting in lowering tensile properties for this recycled product. This also indicates that the samples with a high waste content (B4 and B5) are to be targeted for use and to replace commercial products similar to $\mathrm{C} 1$ and $\mathrm{C} 2$. However, the commercial products generally show higher stress at break values with a DHT of $195^{\circ} \mathrm{C}$, which was expected because the processing temperature can induce degradation of the waste content during the process stage. Camann et al. [42] reported on the mechanical properties of various commercial grade carrier bags in the US, and the 


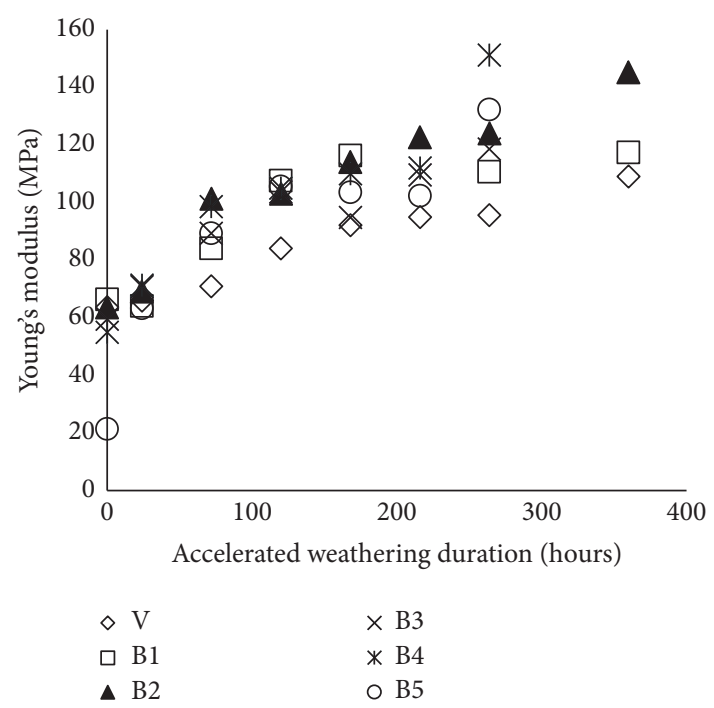

(a)

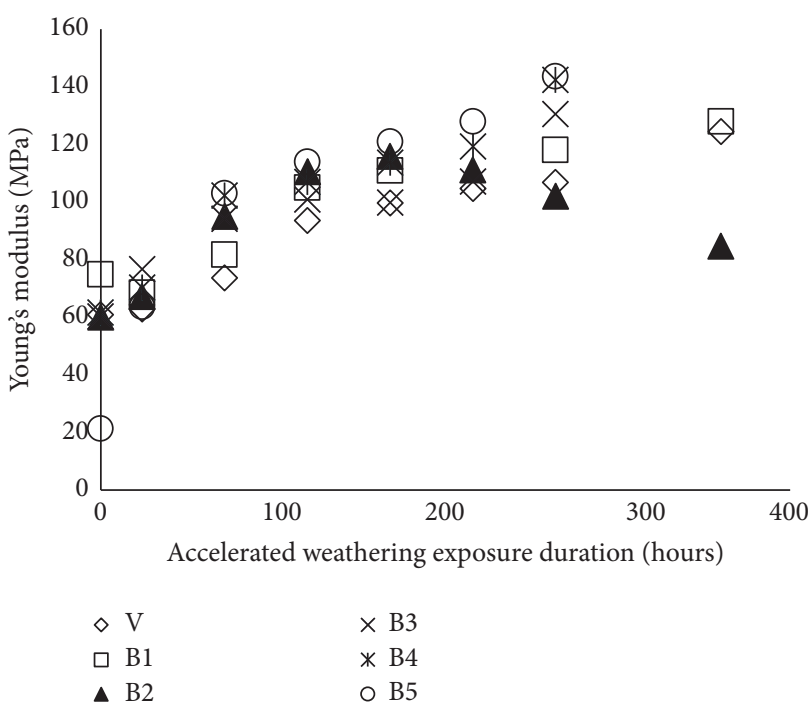

(b)

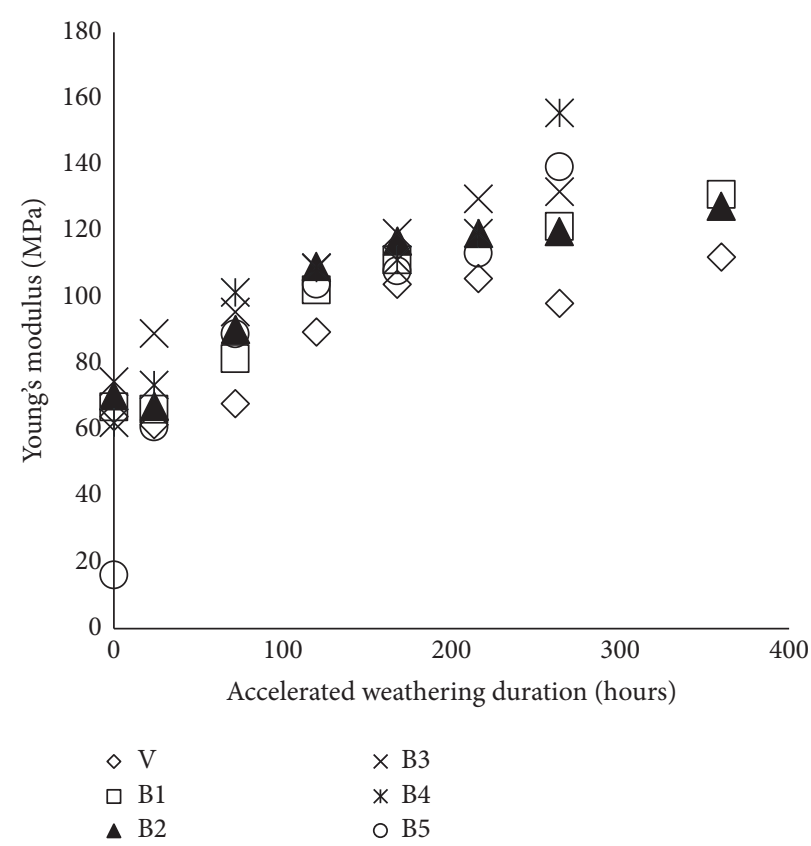

(c)

Figure 4: Young's modulus of the formulated samples with respect to accelerated weathering duration (hours). Samples processed with a Die Head Temperature $(\mathrm{DHT})=175,185$, and $195^{\circ} \mathrm{C}$ are shown in (a), (b), and (c), respectively.

blends tested in this work were all found to be within the mentioned acceptable international and market standards in terms of the mechanical properties.

Strain at break (\%) is reported for the studied samples at the different DHTs in Figure 4. A clear decreasing trend in relation to the waste content is notable in the measured values for all the formulations at the different DHTs. Furthermore, $\mathrm{B} 1$ samples under both DHTs of 175 and $195^{\circ} \mathrm{C}$ did not exhibit a change in terms of strain when compared with virgin resin $(\mathrm{V})$. This indicates that, for other applications where it is desired for strain to be maintained, an amount of $10 \mathrm{wt} \%$ of dry filler could be employed with no effect on the article's integrity. This is in contrast to samples processed at a DHT of $185^{\circ} \mathrm{C}$, where a clear drop is noted in the strain value. This is attributed, similar to the stress at break behaviour, to the immiscibility on a physical level of the polymeric blend at this temperature. Hence, to have a consistent tensile profile for waste blends in terms of tensile properties, the material should be processed at either the virgin or the waste optimal processing temperature which in our case is $175^{\circ} \mathrm{C}$ or $195^{\circ} \mathrm{C}$.

All of the samples measured in this work showed higher strain at break values than $\mathrm{C} 1$ and $\mathrm{C} 2$, evidencing clear superiority of the recycled blends over the virgin resin used in producing local market carrier bag products. In reviewing 
all of the studied formulations of waste and virgin blends, it can be deduced that plastic film waste did not always have a negative impact on the properties that can make the blends acceptable for use as indoor products. In terms of market standards, all material blends showed a comparable mechanical profile to the randomly selected products. This indicates that the plastic film waste in Kuwait did not suffer great degrees of degradation that would render it unusable or unrecyclable, or even in need of blending with other additives (i.e., blowing agents and reinforcing/binding chemicals). In fact, a high content of plastic film waste can be used to produce films that can be of future potential use on the Kuwaiti market. More precisely, formulation B5, which has a waste content of $90 \%$, showed results comparable with the market products, making it potential for new developments in the future. This could result in decreasing the demand on virgin resin grades of plastics in Kuwait, whilst lowering the carbon footprint of the processes involved in producing the carrier bags by the lowering energy demand.

\subsection{Durability of the Formulated Blends. Weathering studies} are typically conducted to determine the threshold limit (i.e., degradation point) and to study the degradation of polymeric products and its effect on materials properties $[3,4,20,26,43-45]$. In this work, accelerated weathering tests were carried out on the formulated blends from virgin and waste materials (i.e., $\mathrm{V}$ and B1-B5) to examine their durability and determine their threshold limits. This investigation was carried out to study the applicability of the formulated blends as a recycled product for various outdoor applications, for example, plastic products, rooftops covers, or insulators. It is crucial to note that past work published in open literature has attempted to establish a correlation between the natural (outdoor) and accelerated (artificial) weathering studies. However, it is recommended that such correlations are only taken as a guideline or an indicator to the threshold limit of the material in outdoor environments [29, $31,46]$. This is because of the number of variables that govern natural weathering that cannot be taken into consideration when performing accelerated weathering tests in controlled environments. However, previous work conducted in Kuwait showing both accelerated and natural weathering (as per similar ASTM standards in a similar geographical location) suggested that $24 \mathrm{~h}$ of exposure to accelerated weathering is equivalent to approximately $430 \mathrm{~h}$ of natural weathering exposure $[20,29]$. This represents a guideline for estimating the lifetime of the material when exposed to the outdoor environment in Kuwait.

The continuous accelerated weathering experiments conducted on the formulated blends revealed that the virgin LLDPE samples (V) compounded with no additives at processing stages withstood $360 \mathrm{~h}$ ( $15 \mathrm{~d}$ ) of continuous exposure in the testing chamber. There were no observed visual signs of deterioration to the samples (e.g., surface damage, deterioration, disintegration, rupture, or cracking). Hence, this limit of exposure did not prevent further experimental characterization of the specimens to evaluate mechanical or physical properties and was considered as the threshold limit of the $\mathrm{V}$ specimens. The same threshold limit was determined for $\mathrm{B} 1$ and $\mathrm{B} 2$ specimens under similar exposure conditions. The B3, B4, and B5 samples had a $260 \mathrm{~h}$ (11 d) threshold limit to continuous weathering, showing the effect of PSW content on the integrity of the plastic products. Indeed, any major surface cracks or physical deformation noted for the samples that prevented further characterization was considered as a sign of reaching the threshold limit of the formulation. The DHT did not have an effect on the threshold limit determined by the accelerated weathering tests performed. The estimated maximum exposure duration of the materials in this study is approximately 9 months under natural weathering conditions, which was based on previous findings [24]. However, it is of paramount to note that metrological conditions and airborne chemicals concentrations interacting with the polymer's surface are continuously changing, especially on the Arabian Peninsula. Therefore, and as previously stated, this is to be considered as a guideline only rather than an exact durability time for outdoors, as previously noted in past works $[26,30,31,46]$.

3.3. Effect of Weathering on the Mechanical Properties of the Virgin/Waste Blends. Figure 4 shows Young's modulus measured for the various samples with respect to weathering duration and showing samples processed with DHTs of 175, 185 , and $195^{\circ} \mathrm{C}$. An increasing trend is observed as a function of exposure duration for all of the tested blends with the various formulations. Virgin LLDPE (V) samples showed the least increase (approximately 30\%) in modulus after a $360 \mathrm{~h}$ exposure compared with the control (no exposure) samples for the three different DHTs. This was anticipated as the virgin (single) polymer samples are more stable in comparison to the blends. Comparatively, an approximately $50 \%$ increase in modulus is observed in all of the formulated blends at the threshold limit of the $\mathrm{V}$ samples, indicating more stiffness when compared to the virgin LLDPE. The V samples processed with a DHT equal to $195^{\circ} \mathrm{C}$ had the lowest modulus value at the end of the weathering test (Figure 4(c)), indicating that a higher DHT leads to a more stable material for the exposure time used, in terms of Young's modulus. Previous reports show that the modulus is governed both by the crystallinity of the material, in this case the polymers constituting each blend, and by the changes brought about by the continuous exposure $[11,47]$. The physical contact during the compounding stages with an elevated temperature of $195^{\circ} \mathrm{C}$ is much higher due to generated heat leading to better stability of the resulting blend [48]. In addition, both PE and $\mathrm{PP}$ in the blends are very susceptible to UV irradiation, and the mechanism of degradation has been reported previously in detail by Philip et al. [21]. This effect leads to the loss of the amorphous region in the polymer matrix due to cross-linking reactions, which results in a change in the modulus measured at various intervals of accelerated weathering, as indicated by the change in the stiffness of the samples (Figure 4).

It can also be noticed that a higher proportion of waste by weight increases the modulus incrementally for B1 to B5 samples. However, samples processed at a DHT of $195^{\circ} \mathrm{C}$ exhibit a lower modulus than the ones processed at a DHT equal to 175 or $185^{\circ} \mathrm{C}$ (Figures $4(\mathrm{a})$ and $4(\mathrm{~b})$ ). The use of higher temperatures during the processing stage will result in 
a different crystallinity of the polymer blend, which is due to the rapid cooling the product undergoes at the final production stage. Alteration in crystallinity due to UV exposure in weathering is also suspected to be the reason of minor surface cracks in the films due to surface contraction and shrinkage [48]. The waste content blended with the virgin polymer contains a number of materials with a processing history that affects their physical and chemical properties. The PE content in the waste underwent three heating cycles, from the initial conversion of the resin to produce the various films that ended up in the PSW stream to the pelletizing and processing stages in the mechanical recycling blending conducted for the benefit of this work. Hence, it is expected that oxidation at the processing stage resulting in hydroperoxide formation will impact the integrity of the samples and consequently the resulting mechanical properties [21]. A similar argument could be made for the PP content in the waste because such phenomena are reported for both polyolefin polymers. It is also worth noting that samples with 10 and $25 \mathrm{wt} \%$ content of waste processed at a DHT of $185^{\circ} \mathrm{C}$ (Figure $4(\mathrm{~b})$ ) showed the least stable modulus trend amongst all of the studied formulations including the virgin LLDPE. This conforms with previous findings that at this DHT the blend is not mixed optimally and shows signs of immiscibility on a physical level.

The stress at break $(\mathrm{MPa})$ is reported with respect to the duration of the accelerated weathering exposure in Figure 5. Samples of the virgin polymer (V) at the three DHTs clearly show superiority over the waste blends in withstanding higher stress after different exposure durations. The initial cross-linking of the polymers leading to a reduction in the molecular weight results in the development of a peak (yield) point after approximately $50 \mathrm{~h}$ of exposure. Such behaviour has been reported previously for virgin polymers $[1,6,20,24$, 49]. Samples B1 to B5 at various DHTs show very similar values of stress at break, almost identical towards the threshold limit, eliminating the processing effect on waste blends at the indicated weight ratios. However, the yield point is clearer and can be easily observed in samples processed at a DHT of $195^{\circ} \mathrm{C}$ (Figure 5(c)). This can be attributed to the polymers undergoing more cross-linking in the initial stages at a higher DHT. From the observed behaviour that the materials are showing, it is worth mentioning that stress at break (rupture) is highly dependent on the hours of exposure to UV. This indicated that such materials, which are to be used for outdoor applications, must be implemented in applications that cannot be jeopardised by the loss of mechanical integrity with UV exposure, as expressed in Figure 5. Such applications include plastic protection for storage products and lorry car covers. The variation between the heating and cooling temperatures at compounding stages and changes in DHT was also evident in the observed trends. It was clearly noted that samples with least amount of plastic waste (B5) had an increase in stress values at the end of weathering test, namely, for samples processed under a DHT of $185^{\circ} \mathrm{C}$ (Figure 5(b)). This can be due to the temperature profile generated between the water temperature of the extruder and the DHT which results in high crystalline zones of $\mathrm{PE}$ that alters its behaviour in this manner [50]. A clear trend showing the effect of the waste addition on the virgin materials is shown in Figure 6, indicating a change in the strain at break values (\%) against weathering durations. The strain values of the $185^{\circ} \mathrm{C}$ samples showed a more rapid decrease especially during the first two days of exposure to accelerated weathering (Figure 6(b)). This can be attributed to crystallinity variation in samples due to the DHT, which makes the 175 and $195^{\circ} \mathrm{C}$ more desirable for a more consistent blend.

The $\mathrm{V}$ samples processed at a DHT of $175^{\circ} \mathrm{C}$ show a rapid decrease in strain values after approximately $50 \mathrm{~h}$ of weathering (Figure 6(a)). Comparatively, the V samples processed at a DHT of 185 and $195^{\circ} \mathrm{C}$ (Figures 6(b) and 6(c)) maintained their original values until approximately $60 \mathrm{~h}$ of exposure. Recycled blends showed a rapid decrease in strain values after approximately $36 \mathrm{~h}$ of exposure. All of the sample tests reached near zero values by the end of the weathering experiment regardless of the DHT. This behaviour can be related to chain scission in the semicrystalline polymers, which leads to a decrease in the molecular weight of the material and consequently to a loss in the strain and elongation at break with weathering [23, 49]. The effect of cross-linking is more clear at the later stages of the weathering of the blends, where a small increase is indicated in strain values for all DHT formulated blends. Such exposure durations could be targeted in product development with recycled materials because the integrity of the plastic is still preserved for each blend at each indicated time of exposure. Hence, certain products, such as the covers used for trucks, rooftops for households, and automobiles, could be developed from these blends. The loss of mechanical integrity can be attributed to the oxidation products that result from photodegradation as indicated previously by Pilar et al. [2]. It was also evident that major cross-linking of the polymers' matrix took place in all studied formulations after approximately $250 \mathrm{~h}$ of exposure, and the effect is shown on the graph as a sharp increase in strain values resulting from major UV degradation, as previously observed by Salem [16]. Polyolefin polymers, namely, LDPE and LLDPE, tend to cross-link rapidly with UV exposure as indicated previously. However, this phenomenon can be related also to the loss of mechanical properties prior to weathering. It can result from the heat processing of the blends which leads to the increase in Young's modulus and decrease of strain values towards the end of weathering spans. The same reasoning can be argued and taken as the rationale for the loss of the stress at break, where the samples tend to have a yield point and then drop towards the end of the weathering duration. The photooxidation effect can be overcome by using stabilizers to this effect $[51,52]$. Photooxidation is considered the main pathway of degradation polymer face in weathering. In this work, the waste content seemed to act as a pseudo-polymer in the blends formulated with the virgin LLDPE at all DHT. This indicates that photooxidation degraded the waste samples in an equivalent manner.

\subsection{Physical (Optical) Properties of the Formulated Blends with} respect to Accelerated Weathering Exposure. Light transmission was measured for the blends studied and reported in Figure 7. The B1 and B2 samples are more transparent in comparison with the $\mathrm{V}$ samples processed at the different 


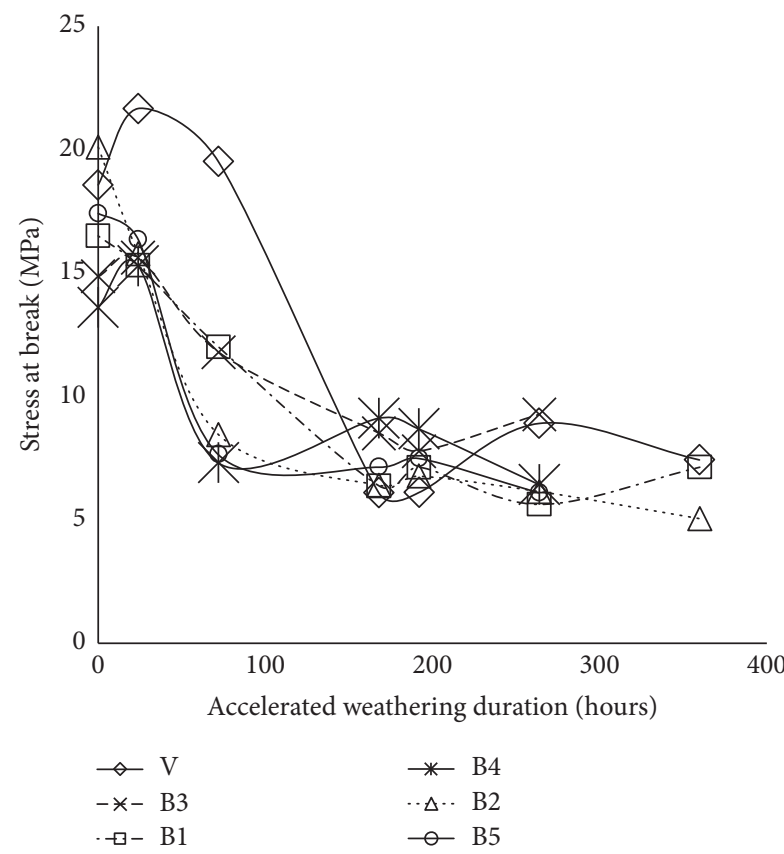

(a)

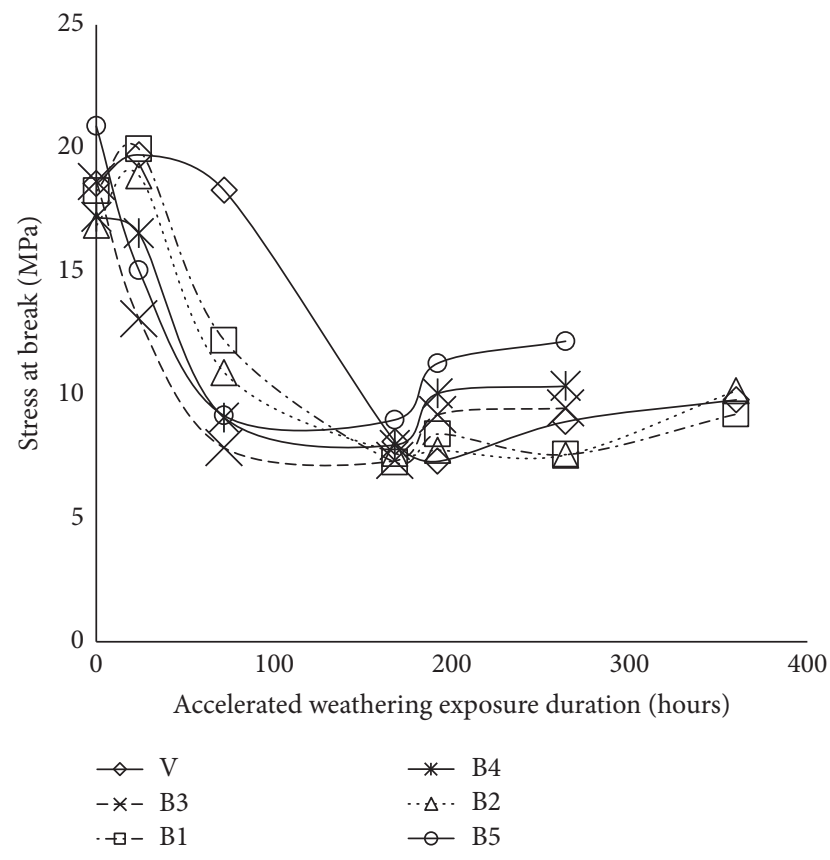

(b)

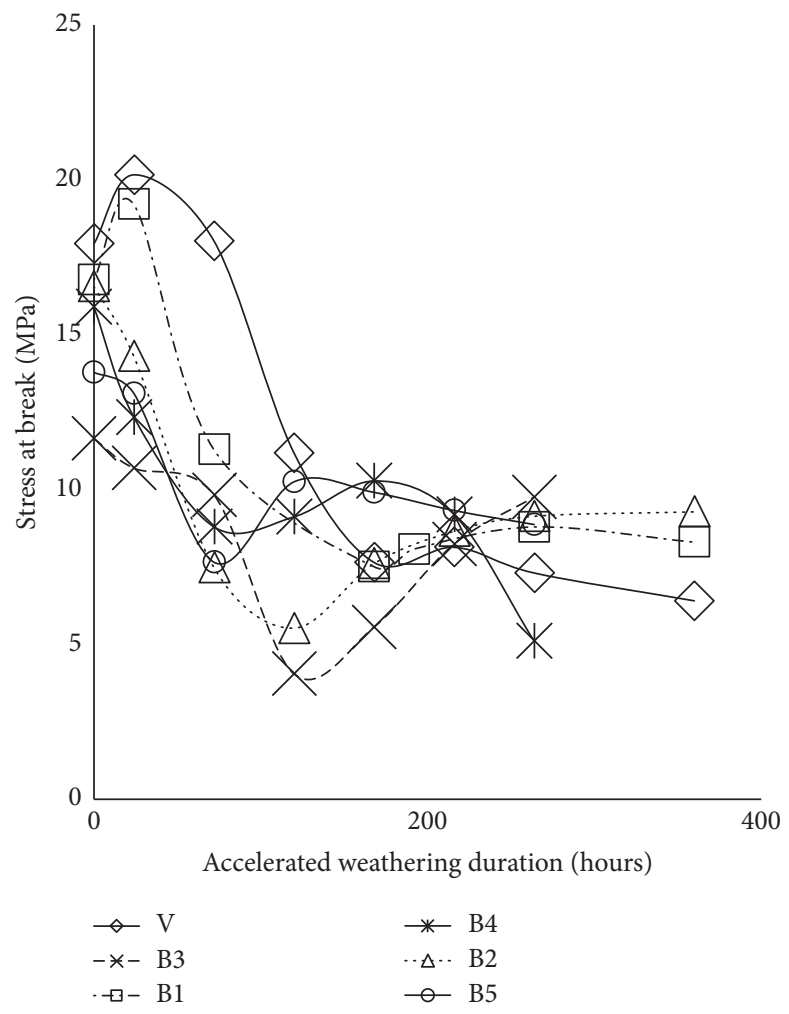

(c)

Figure 5: Stress at break for studied blends formulated using Die Head Temperature (DHT) equal to $175^{\circ} \mathrm{C} \mathrm{(a),} 185^{\circ} \mathrm{C}$ (b), and $195^{\circ} \mathrm{C}$ (c).

DHTs. This could be attributed to the low amount of waste material in the blend leaving voids that make the samples more transparent than the single polymer product (V). However, samples processed at a DHT of $195^{\circ} \mathrm{C}$ were generally more transparent than the samples processed at 175 and $185^{\circ} \mathrm{C}$. Binding and miscibility at processing stages are considered the two key factors that govern transparency in polymeric materials $[3,13,27]$. Samples containing more than $50 \mathrm{wt} \%$ of plastic film waste start to lose their transparency more rapidly because of the high amount of components the 


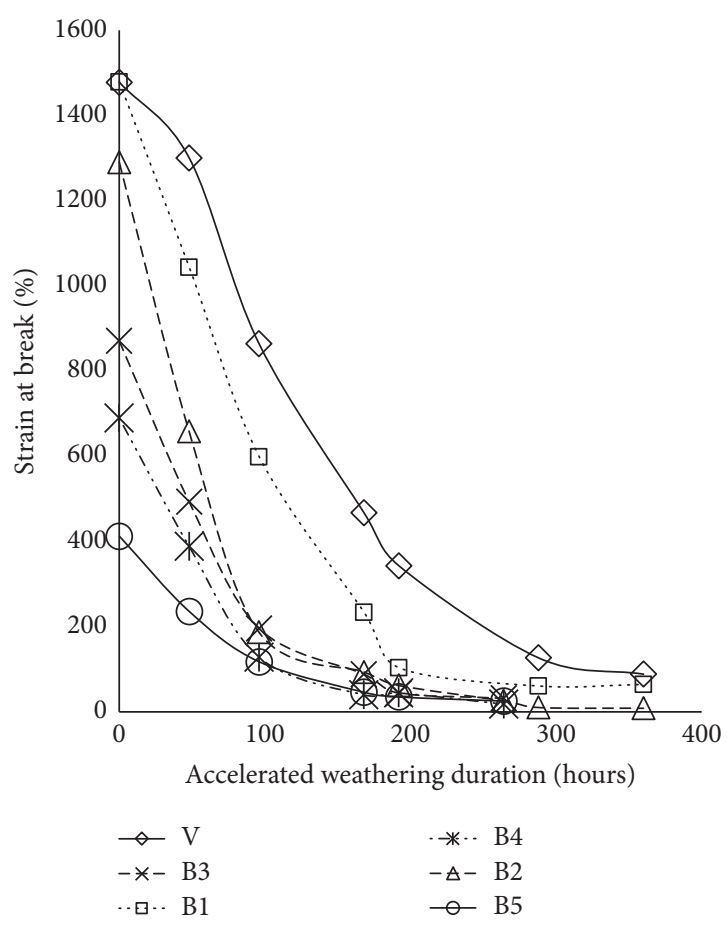

(a)

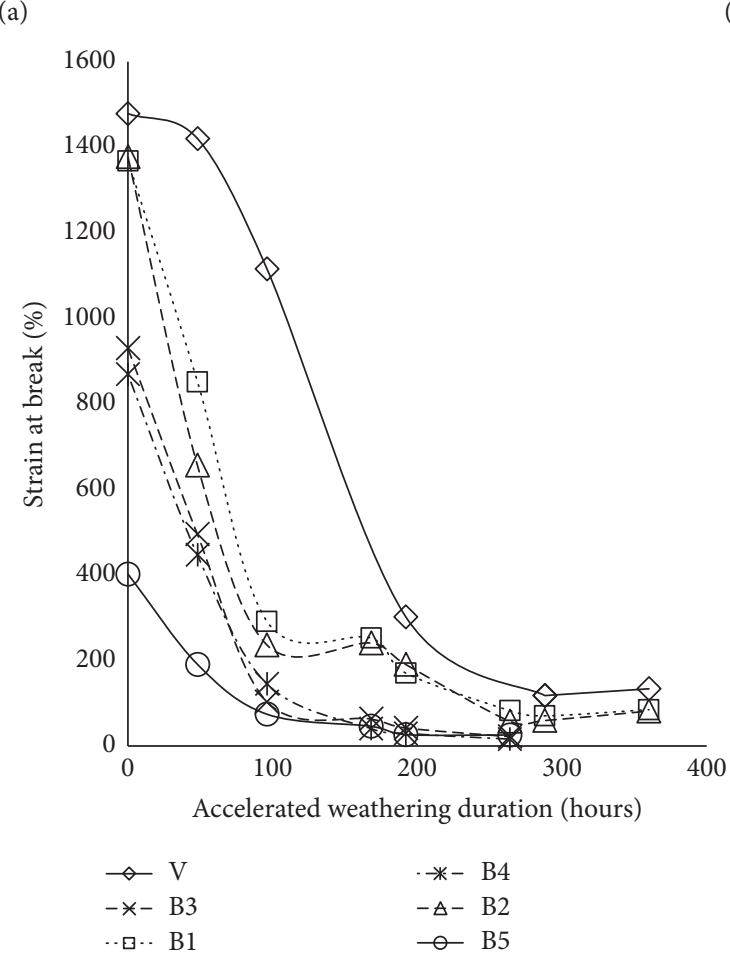

(c)

FIGURE 6: Strain at break (\%) of the formulated samples with respect to accelerated weathering duration (days). Samples processed with a Die Head Temperature $(\mathrm{DHT})=175,185$, and $195^{\circ} \mathrm{C}$ are shown in (a), (b), and (c), respectively.

waste materials contain. The transmission measured showed the highest change among samples processed with a DHT equal to $195^{\circ} \mathrm{C}$ due to higher temperature profile developed between cooling and heating cycles at compounding stages. This leads to larger crystalline regions among the polymer

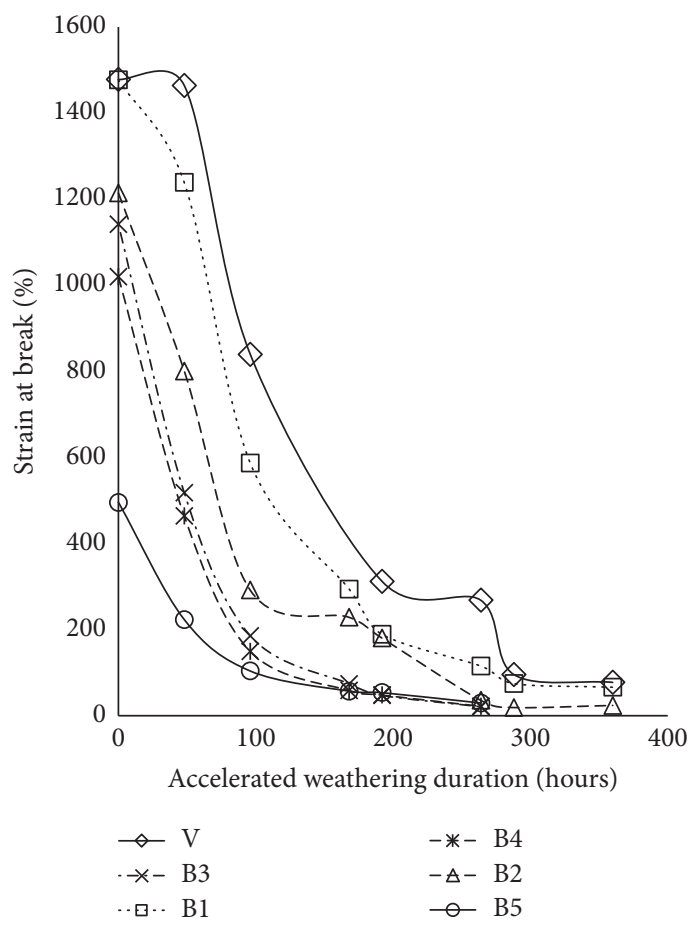

(b) 


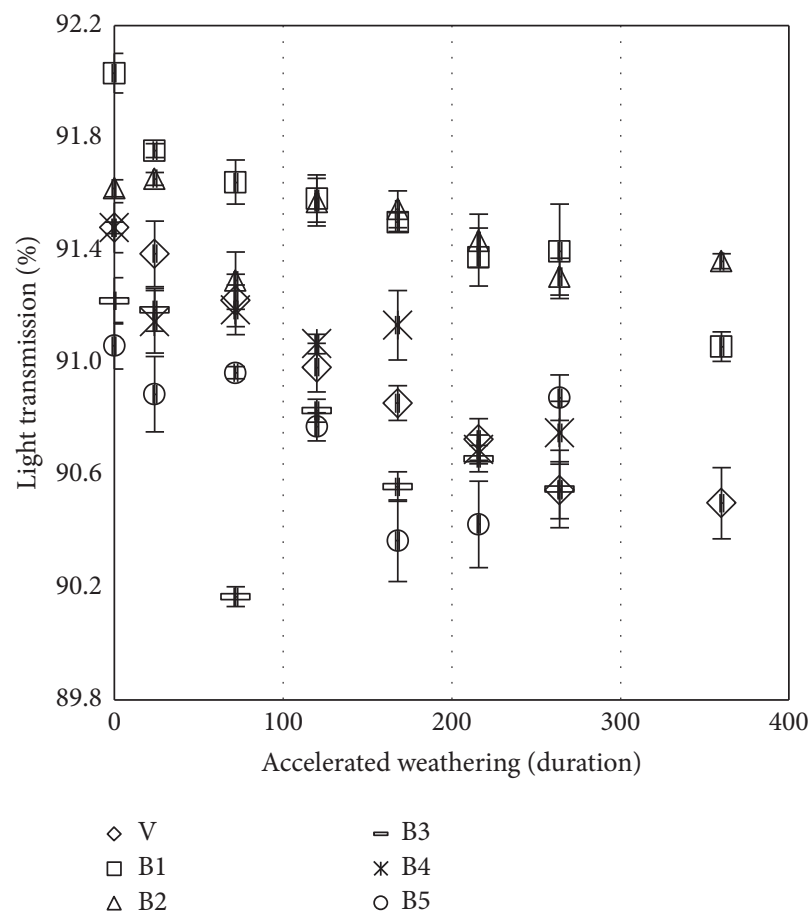

(a)

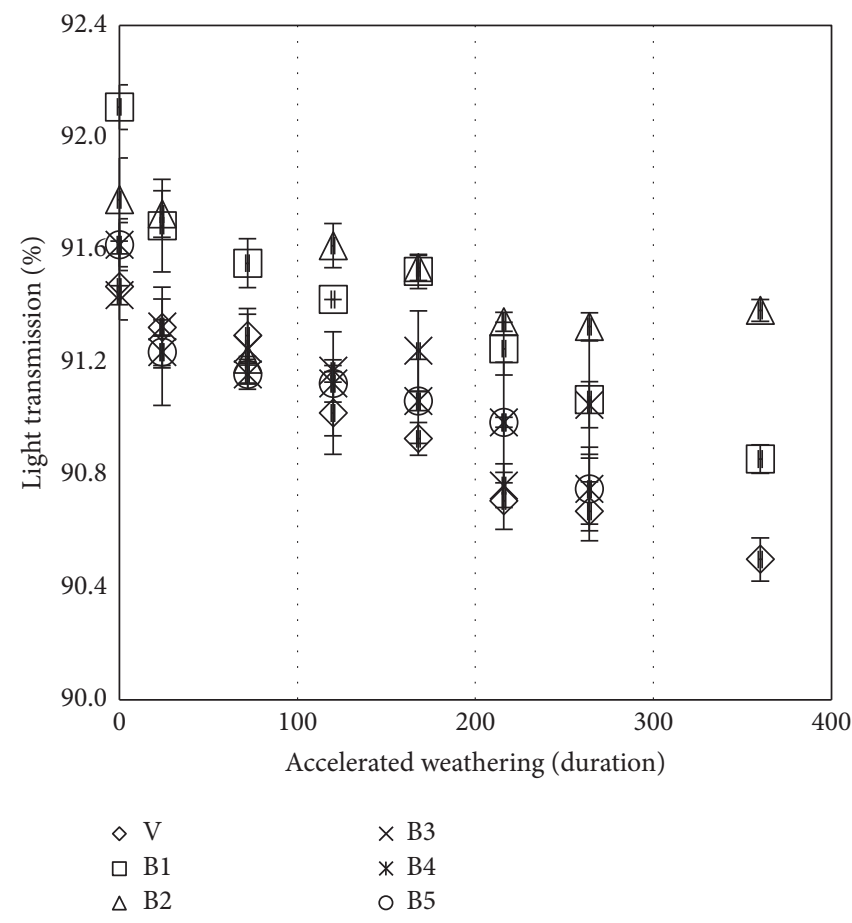

(b)

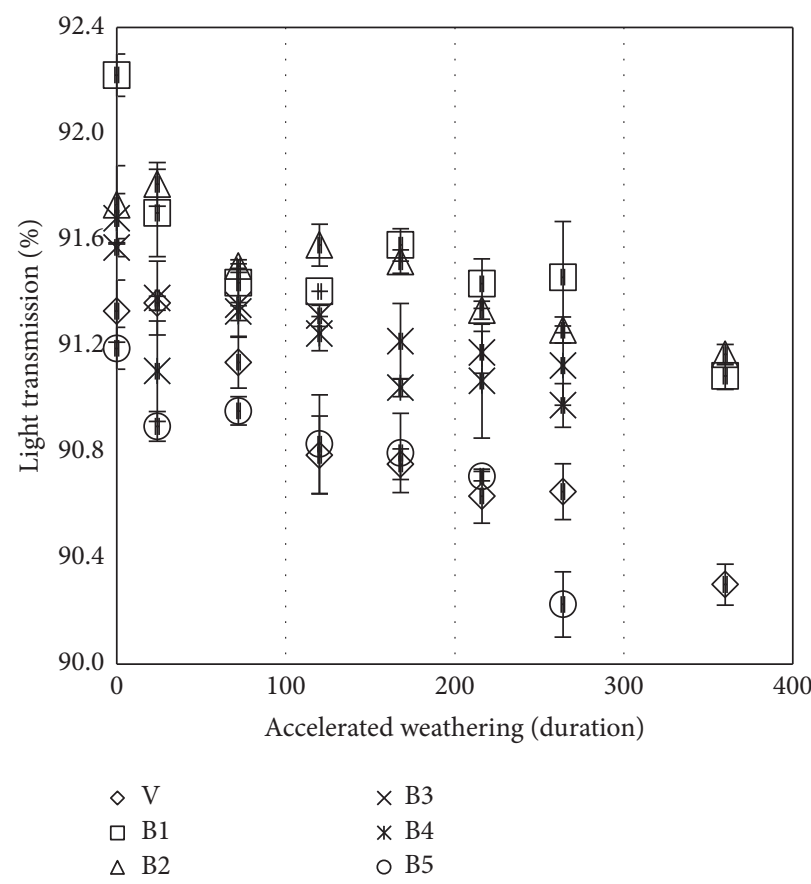

(c)

FIGURE 7: Light transmission (\%) of the formulated samples with respect to accelerated weathering duration (days). Samples processed with a Die Head Temperature $(\mathrm{DHT})=175,185$, and $195^{\circ} \mathrm{C}$ are shown in (a), (b), and (c), respectively.

sunny climates when plastic products are manufactured for outdoor applications. V samples showed a very similar trend amongst all three of the tested DHT batches indicating a lack of dependency of haze (\%) on the processing conditions. Because other materials that constituted various amounts of waste showed a clear shift in haze values, it can be concluded that haze is dependent on the type of material and the hours of UV exposure, rather than the processing conditions of the material. This can be attributed to the fact that haze in plastic grade products is the result of the voids between the molecules of the polymeric matrix, which, once they are set after cooling in the compounding stage, do not alter in terms 

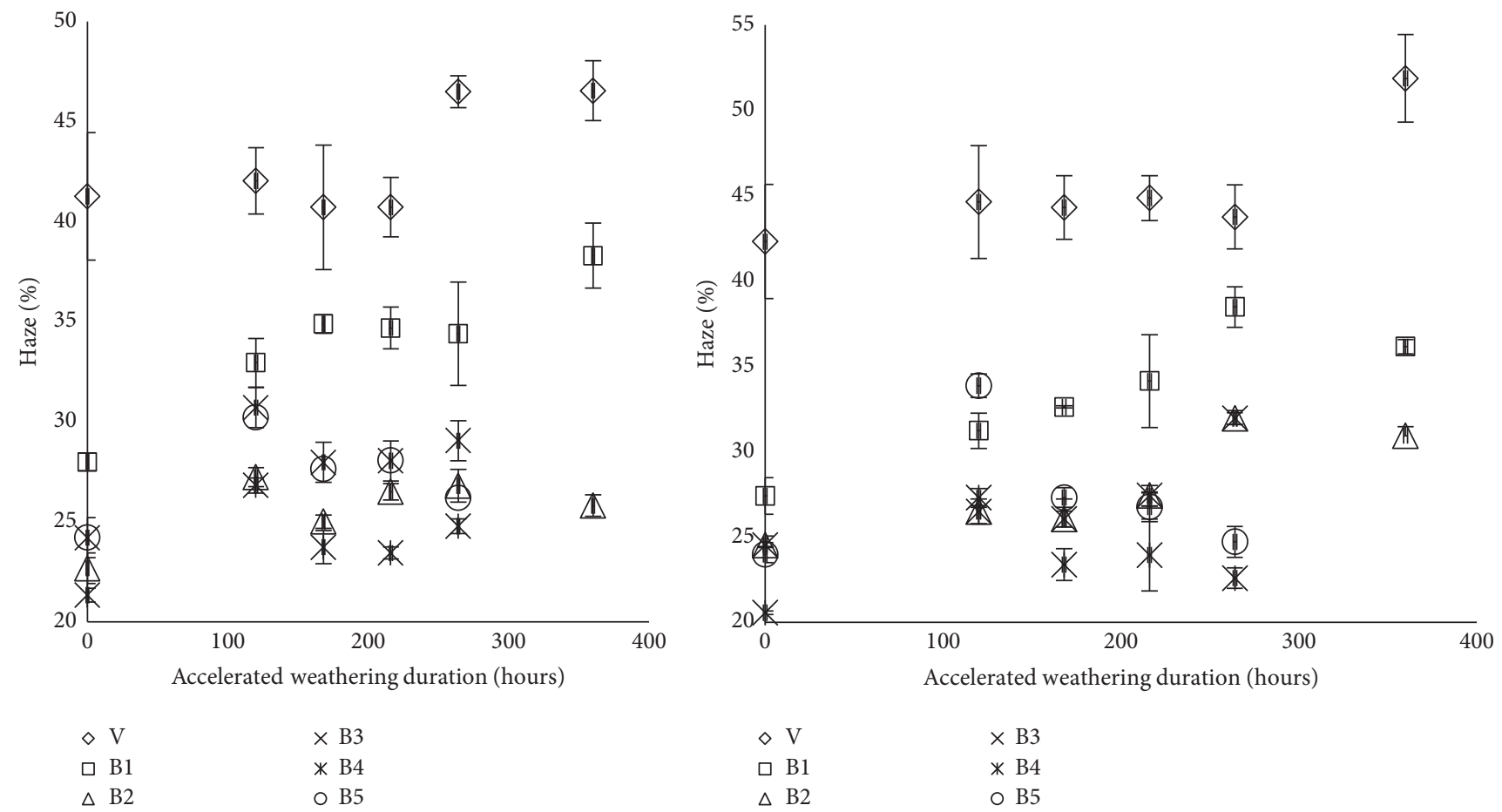
$\diamond \mathrm{V}$
$\times$ B3
B1
$*$ B4
O B5

(a)

(b)

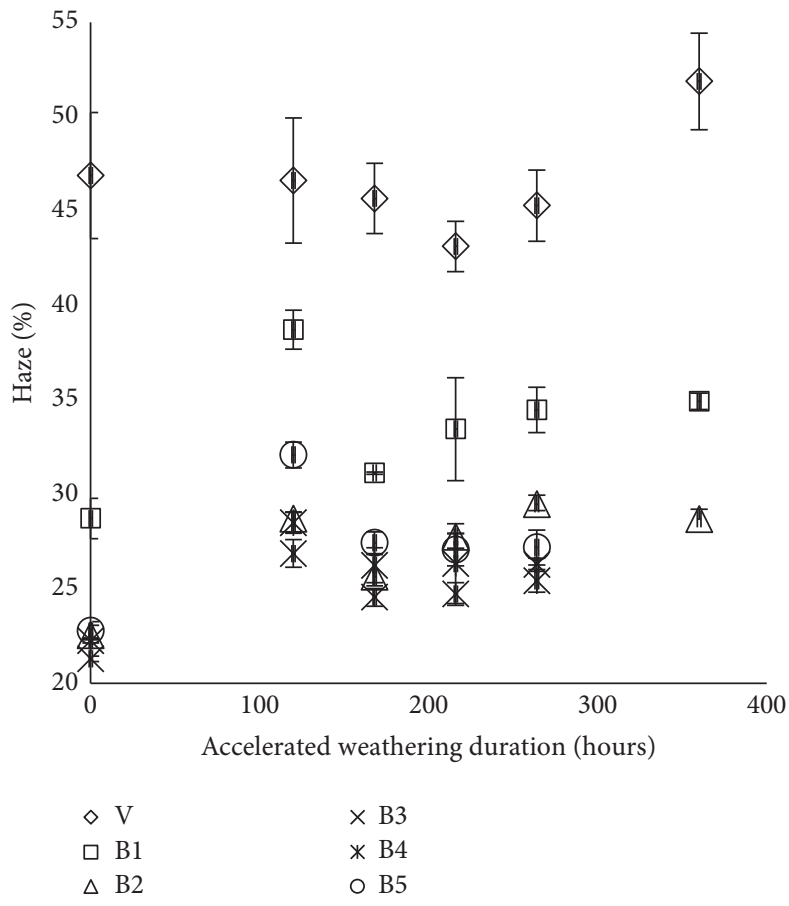

(c)

Figure 8: Haze (\%) of the formulated samples with respect to accelerated weathering duration (days). Samples processed with a Die Head Temperature $(\mathrm{DHT})=175,185$, and $195^{\circ} \mathrm{C}$ are shown in (a), (b), and (c), respectively.

of physical properties. The change that occurs with respect to cross-linking and chain scission in the polymer matrix affects other properties, as previously noted. However, the size of the molecules in the crystalline region does not alter with DHT but is controlled by the cooling rate in the processing stage, which on the other hand does not affect the haze values measured with respect to different DHTs among the tested formulations.

Dehbi et al. $[6,52]$ discussed changes in the physical properties of polymeric products, namely, their yellow colour. 
TABLE 1: Control samples (no exposure) colour parameters.

\begin{tabular}{cccc}
\hline & $L_{s}^{*}$ & $a_{s}^{*}$ & $b_{s}^{*}$ \\
\hline Materials (wt/wt\%), DHT $=175^{\circ} \mathrm{C}$ & & & \\
V (100 LLDPE/0 waste) & 29.0 & -0.40 & -3.5 \\
B1 (90 LLDPE/10 waste) & 26.0 & -0.80 & -4.53 \\
B2 (75 LLDPE/25 waste) & 25.2 & -0.40 & -4.8 \\
B3 (50 LLDPE/50 waste) & 23.0 & -0.60 & -5.9 \\
B4 (25 LLDPE/75 waste) & 20.1 & -0.50 & -5.6 \\
B5 (10 LLDPE/90 waste) & 18.0 & -0.40 & -5.5 \\
Materials (wt/wt\%), DHT $=185^{\circ} \mathrm{C}$ & & & \\
V (100 LLDPE/0 waste) & 27.0 & -0.12 & -3.68 \\
B1 (90 LLDPE/10 waste) & 25.3 & -0.58 & -4.42 \\
B2 (75 LLDPE/25 waste) & 25.2 & -0.51 & -4.81 \\
B3 (50 LLDPE/50 waste) & 24.29 & -0.47 & -5.47 \\
B4 (25 LLDPE/75 waste) & 21.6 & -0.47 & -5.49 \\
B5 (10 LLDPE/90 waste) & 17.97 & -0.36 & -5.7 \\
Materials (wt/wt\%), DHT $=195^{\circ} \mathrm{C}$ & & & \\
V (100 LLDPE/0 waste) & 27.6 & -0.40 & -3.95 \\
B1 (90 LLDPE/10 waste) & 6.9 & -0.60 & -4.24 \\
B2 (75 LLDPE/25 waste) & 24.8 & -0.41 & -5.01 \\
B3 (50 LLDPE/50 waste) & 23.6 & -8.10 & -5.52 \\
B4 (25 LLDPE/75 waste) & 21.0 & -0.41 & -5.70 \\
B5 (10 LLDPE/90 waste) & 16.9 & -0.31 & -5.44 \\
\hline
\end{tabular}

In this work, colour parameters were measured and are reported in Tables 1-4, indicating the total change in colour for the studied blends. The effect of UV exposure was evident in terms of the difference of the total change in colour $(\Delta E)$ with respect to exposure time. However, no clear trend was observed in the colour parameter measurements with respect to exposure time, indicating that the condensation mechanism in the weathering chamber is a main factor that controls the change in colour, as noted in some previous works [39]. In addition, it was observed that photo-bleaching and a change in surface chemistry were a function of waste content in the formulation, leading to more discolouration $(\Delta E)$ with higher waste content. Discolouration was noted on the surface of the samples as weathering time increased. This indicates that water absorption can take place in the polymer's structure and change the orientation of the molecules due to water spray and condensation occurring in accelerated weathering [49]. It can also be noted that the colouring of the products could be desirable to consumers; however, the use of pigments presents costs that converters prefer to avoid. Therefore, based on the findings of this work, it would be advised to use the product with no colouring unless it was demanded by plastic product converters, for which water soluble pigments would be recommended to avoid alteration of the properties measured. The breakage of the $\mathrm{CH}_{2}-\mathrm{CH}_{2}$ chains in PE results in an increase of the free surface energy that causes faster degradation of the polymer films [45]. This on the other hand and with progression of the accelerated weathering can lead to loss of yellow colour passing through a minimum level (corresponding to disappearance of present dye present in commercial
TABLE 2: Colour parameters and total change in colour $(\Delta E)$ for studied formulations at different accelerated weathering exposure (hours) processed at a $\mathrm{DHT}=175^{\circ} \mathrm{C}$.

\begin{tabular}{|c|c|c|c|c|c|}
\hline $\begin{array}{l}\text { Materials } \\
\text { (wt.\%/wt.\%) }\end{array}$ & $\begin{array}{c}\text { Exposure } \\
\text { duration } \\
\text { (hours) }\end{array}$ & $L_{s}^{*}$ & $a_{s}^{*}$ & $b_{s}^{*}$ & $\Delta E$ \\
\hline \multirow{7}{*}{$\begin{array}{l}\mathrm{V}(100 \mathrm{LLDPE} / 0 \\
\text { waste) }\end{array}$} & 48 & 27.0 & -0.7 & -4.5 & $2.2 \pm 0.1$ \\
\hline & 72 & 26.6 & 0.2 & -4.3 & $2.5 \pm 0.2$ \\
\hline & 120 & 26.0 & -0.3 & -4.5 & $3.3 \pm 0.1$ \\
\hline & 168 & 28.6 & -0.3 & -3.9 & $0.6 \pm 0.4$ \\
\hline & 216 & 26.1 & -0.1 & -4.2 & $3.0 \pm 0.3$ \\
\hline & 264 & 29.1 & -0.04 & -4.0 & $0.6 \pm 0.4$ \\
\hline & 360 & 28.5 & -0.07 & -3.9 & $0.8 \pm 0.2$ \\
\hline \multirow{7}{*}{$\begin{array}{l}\text { B1 (90 LLDPE/10 } \\
\text { waste) }\end{array}$} & 48 & 27.9 & 0.5 & -3.8 & $2.4 \pm 0.2$ \\
\hline & 72 & 24.4 & -0.2 & -6.5 & $2.5 \pm 0.2$ \\
\hline & 120 & 27.7 & -0.1 & -4.6 & $1.8 \pm 0.1$ \\
\hline & 168 & 27.4 & -0.2 & -4.5 & $1.5 \pm 0.1$ \\
\hline & 216 & 26.7 & -0.3 & -4.7 & $0.9 \pm 0.1$ \\
\hline & 264 & 19.0 & 0.2 & -5.8 & $7.1 \pm 0.2$ \\
\hline & 360 & 31.1 & -0.05 & -4.1 & $5.2 \pm 0.2$ \\
\hline \multirow{7}{*}{$\begin{array}{l}\text { B2 (75 LLDPE/25 } \\
\text { waste) }\end{array}$} & 48 & 26.4 & -0.7 & -3.8 & $1.4 \pm 0.5$ \\
\hline & 72 & 24.4 & -0.1 & -6.4 & $1.8 \pm 0.2$ \\
\hline & 120 & 26.4 & -0.1 & -5.6 & $1.8 \pm 0.1$ \\
\hline & 168 & 26.1 & -0.3 & -5.6 & $1.2 \pm 0.3$ \\
\hline & 216 & 26.5 & -0.4 & -5.2 & $1.2 \pm 0.2$ \\
\hline & 264 & 28.2 & -0.1 & -5.0 & $3.0 \pm 0.1$ \\
\hline & 360 & 26.8 & 0.05 & -5.0 & $1.7 \pm 0.1$ \\
\hline \multirow{6}{*}{$\begin{array}{l}\text { B3 (50 LLDPE/50 } \\
\text { waste) }\end{array}$} & 48 & 28.6 & -0.7 & -7.0 & $5.7 \pm 0.8$ \\
\hline & 72 & 26.6 & -0.3 & -6.6 & $3.7 \pm 0.1$ \\
\hline & 120 & 24.5 & -0.1 & -6.5 & $1.7 \pm 0.3$ \\
\hline & 168 & 22.2 & -0.2 & -6.0 & $2.1 \pm 0.1$ \\
\hline & 216 & 24.4 & -0.2 & -6.0 & $1.5 \pm 0.1$ \\
\hline & 264 & 28.2 & 0.0 & -6.2 & $5.3 \pm 0.1$ \\
\hline \multirow{6}{*}{$\begin{array}{l}\text { B4 (25 LLDPE/75 } \\
\text { waste) }\end{array}$} & 48 & 22.4 & -0.5 & -5.4 & $2.3 \pm 0.3$ \\
\hline & 72 & 22.2 & -0.1 & -6.2 & $2.2 \pm 0.1$ \\
\hline & 120 & 21.3 & -0.1 & -6.0 & $1.3 \pm 0.4$ \\
\hline & 168 & 21.8 & -0.2 & -6.2 & $1.8 \pm 0.1$ \\
\hline & 216 & 22.2 & -0.2 & -6.0 & $2.1 \pm 0.1$ \\
\hline & 264 & 24.2 & 0.05 & -6.3 & $4.1 \pm 0.2$ \\
\hline \multirow{6}{*}{$\begin{array}{l}\text { B5 (10 LLDPE/90 } \\
\text { waste) }\end{array}$} & 48 & 19.0 & -0.5 & -6.2 & $1.1 \pm 0.3$ \\
\hline & 72 & 19.0 & -0.5 & -6.2 & $1.1 \pm 0.2$ \\
\hline & 120 & 20.2 & -0.1 & -5.9 & $2.2 \pm 0.2$ \\
\hline & 168 & 19.8 & -0.2 & -5.7 & $1.7 \pm 0.2$ \\
\hline & 216 & 19.3 & -0.1 & -5.7 & $1.2 \pm 0.2$ \\
\hline & 264 & 19.0 & 0.1 & -5.7 & $1.1 \pm 0.2$ \\
\hline
\end{tabular}

grades) and an increase in the level of yellowness due to the degradation process itself. Moreover, large crystalline zones are reported to form with accelerated weathering in past research and surface chemistry changes are noted to take place on the basis of the fluctuating $\Delta E$ results obtained [54]. 
TABLE 3: Colour parameters and total change in colour $(\Delta E)$ for studied formulations at different accelerated weathering exposure (hours) processed at a $\mathrm{DHT}=185^{\circ} \mathrm{C}$.

\begin{tabular}{|c|c|c|c|c|c|}
\hline $\begin{array}{l}\text { Materials } \\
\text { (wt.\%/wt.\%) }\end{array}$ & $\begin{array}{l}\text { Exposure } \\
\text { duration } \\
\text { (hours) }\end{array}$ & $L_{s}^{*}$ & $a_{s}^{*}$ & $b_{s}^{*}$ & $\Delta E$ \\
\hline \multirow{7}{*}{$\begin{array}{l}\mathrm{V}(100 \mathrm{LLDPE} / 0 \\
\text { waste) }\end{array}$} & 48 & 26.8 & -0.54 & -4.15 & $0.65 \pm 0.2$ \\
\hline & 72 & 26.74 & 0.03 & -4.41 & $0.8 \pm 0.3$ \\
\hline & 120 & 27.30 & -0.20 & -4.22 & $1.2 \pm 0.4$ \\
\hline & 168 & 27.91 & -0.19 & -4.24 & $1.05 \pm 0.2$ \\
\hline & 216 & 26.2 & -0.2 & -4.7 & $1.6 \pm 0.1$ \\
\hline & 264 & 29.55 & 0 & -4.2 & $2.58 \pm 0.2$ \\
\hline & 360 & 29.82 & -0.13 & -4.07 & $2.8 \pm 0.2$ \\
\hline \multirow{7}{*}{$\begin{array}{l}\text { B1 (90 LLDPE/10 } \\
\text { waste) }\end{array}$} & 48 & 27.32 & -0.52 & -4.58 & $1.9 \pm 0.1$ \\
\hline & 72 & 30.0 & -0.2 & -4.4 & $3.2 \pm 0.3$ \\
\hline & 120 & 30.1 & -0.05 & -3.9 & $4.8 \pm 0.4$ \\
\hline & 168 & 26.38 & -0.28 & -4.77 & $1.1 \pm 0.2$ \\
\hline & 216 & 18.83 & 0.36 & -6.17 & $6.82 \pm 0.1$ \\
\hline & 264 & 21.9 & 0.1 & -6.6 & $5.5 \pm 0.3$ \\
\hline & 360 & 31.05 & -0.10 & -4.28 & $5.71 \pm 0.1$ \\
\hline \multirow{7}{*}{$\begin{array}{l}\text { B2 (75 LLDPE/25 } \\
\text { waste) }\end{array}$} & 48 & 26.95 & -0.62 & -4.60 & $1.68 \pm 0.1$ \\
\hline & 72 & 26.78 & -0.24 & -6.3 & $2.1 \pm 0.3$ \\
\hline & 120 & 26.29 & -0.16 & -5.4 & $1.22 \pm 0.1$ \\
\hline & 168 & 26.3 & -0.23 & -5.3 & $1.24 \pm 0.1$ \\
\hline & 216 & 26.2 & -0.30 & -4.8 & $1.01 \pm 0.1$ \\
\hline & 264 & 29.5 & 0 & -4.7 & $4.3 \pm 0.3$ \\
\hline & 360 & 30.06 & -0.05 & -4.76 & $4.8 \pm 0.2$ \\
\hline \multirow{6}{*}{$\begin{array}{l}\text { B3 (50 LLDPE/50 } \\
\text { waste) }\end{array}$} & 48 & 25.3 & -0.77 & -5.7 & $1.16 \pm 0.2$ \\
\hline & 72 & 24.1 & -0.12 & -5.87 & $0.54 \pm 0.1$ \\
\hline & 120 & 24.11 & -0.04 & -5.84 & $0.58 \pm 0.2$ \\
\hline & 168 & 24.8 & -0.21 & -5.9 & $0.7 \pm 0.0$ \\
\hline & 216 & 26.71 & -0.33 & -6.1 & $2.5 \pm 0.1$ \\
\hline & 264 & 26.06 & -0.15 & -5.6 & $1.8 \pm 0.1$ \\
\hline \multirow{6}{*}{$\begin{array}{l}\text { B4 (25 LLDPE/75 } \\
\text { waste) }\end{array}$} & 48 & 24.11 & -0.51 & -5.86 & $2.5 \pm 0.1$ \\
\hline & 72 & 21.6 & -0.05 & -6.0 & $0.8 \pm 0.2$ \\
\hline & 120 & 21.2 & -0.14 & -5.75 & $0.3 \pm 0.1$ \\
\hline & 168 & 22.89 & -0.05 & -5.86 & $1.36 \pm 0.1$ \\
\hline & 216 & 22.30 & -0.13 & -13.0 & $7.4 \pm 0.3$ \\
\hline & 264 & 22.4 & 0.3 & -6.0 & $1.2 \pm 0.1$ \\
\hline \multirow{6}{*}{$\begin{array}{l}\text { B5 (10 LLDPE/90 } \\
\text { waste) }\end{array}$} & 48 & 22.57 & 0.55 & -5.88 & $4.68 \pm 0.1$ \\
\hline & 72 & 18.56 & -0.39 & -6.7 & $1.16 \pm 0.3$ \\
\hline & 120 & 18.6 & -0.21 & -5.99 & $0.71 \pm 0.1$ \\
\hline & 168 & 26.0 & -0.2 & -4.80 & $1.11 \pm 0.1$ \\
\hline & 216 & 29.97 & 0.21 & -4.43 & $3.11 \pm 0.3$ \\
\hline & 264 & 18.83 & 0.36 & -6.17 & $1.21 \pm 0.1$ \\
\hline
\end{tabular}

Hence, a stabilizing agent for the control of physical properties, namely, colour, is also recommended for further product development. This could also lead to a more stable polymeric matrix that can withstand changes on the surface
TABLE 4: Colour parameters and total change in colour $(\Delta E)$ for studied formulations at different accelerated weathering exposure (hours) processed at a $\mathrm{DHT}=195^{\circ} \mathrm{C}$.

\begin{tabular}{|c|c|c|c|c|c|}
\hline $\begin{array}{l}\text { Materials } \\
\text { (wt.\%/wt.\%) }\end{array}$ & $\begin{array}{c}\text { Exposure } \\
\text { duration } \\
\text { (hours) }\end{array}$ & $L_{s}^{*}$ & $a_{s}^{*}$ & $b_{s}^{*}$ & $\Delta E$ \\
\hline \multirow{7}{*}{$\begin{array}{l}\mathrm{V}(100 \mathrm{LLDPE} / 0 \\
\text { waste) }\end{array}$} & 48 & 25.8 & -0.6 & -4.7 & $2.0 \pm 0.1$ \\
\hline & 72 & 27.0 & 0.0 & -4.3 & $0.8 \pm 0.1$ \\
\hline & 120 & 28.8 & -0.1 & -4.0 & $1.2 \pm 0.4$ \\
\hline & 168 & 26.8 & -0.2 & -4.4 & $1.0 \pm 0.2$ \\
\hline & 216 & 26.2 & -0.2 & -4.7 & $1.6 \pm 0.1$ \\
\hline & 264 & 29.5 & -0.1 & -4.3 & $2.0 \pm 0.2$ \\
\hline & 360 & 30.3 & -0.1 & -3.9 & $2.6 \pm 0.3$ \\
\hline \multirow{7}{*}{$\begin{array}{l}\text { B1 (90 LLDPE/10 } \\
\text { waste) }\end{array}$} & 48 & 28.7 & 0.4 & -4.0 & $2.1 \pm 0.3$ \\
\hline & 72 & 30.0 & -0.2 & -4.4 & $3.2 \pm 0.3$ \\
\hline & 120 & 28.2 & -0.1 & -5.0 & $1.5 \pm 0.1$ \\
\hline & 168 & 26.0 & -0.3 & -4.8 & $1.1 \pm 0.1$ \\
\hline & 216 & 30.0 & -0.2 & -4.4 & $3.1 \pm 0.3$ \\
\hline & 264 & 21.9 & 0.1 & -6.6 & $5.5 \pm 0.3$ \\
\hline & 360 & 29.8 & -0.1 & -4.3 & $3.0 \pm 0.2$ \\
\hline \multirow{7}{*}{$\begin{array}{l}\text { B2 (75 LLDPE/25 } \\
\text { waste) }\end{array}$} & 48 & 26.0 & -0.6 & -4.8 & $1.2 \pm 0.2$ \\
\hline & 72 & 24.5 & -0.1 & -6.0 & $1.1 \pm 0.3$ \\
\hline & 120 & 25.3 & -0.1 & -5.3 & $0.6 \pm 0.1$ \\
\hline & 168 & 27.0 & -0.2 & -4.8 & $2.2 \pm 0.2$ \\
\hline & 216 & 26.6 & -0.2 & -4.8 & $1.8 \pm 0.1$ \\
\hline & 264 & 29.3 & -0.1 & -4.7 & $4.5 \pm 0.1$ \\
\hline & 360 & 28.6 & -0.2 & -4.7 & $3.8 \pm 0.2$ \\
\hline \multirow{6}{*}{$\begin{array}{l}\text { B3 (50 LLDPE/50 } \\
\text { waste) }\end{array}$} & 48 & 23.5 & -0.7 & -5.7 & $7.4 \pm 0.2$ \\
\hline & 72 & 25.1 & -0.2 & -5.5 & $8.0 \pm 0.2$ \\
\hline & 120 & 25.9 & -0.2 & -5.4 & $8.1 \pm 0.2$ \\
\hline & 168 & 25.5 & -0.2 & -5.6 & $8.0 \pm 0.2$ \\
\hline & 216 & 25.0 & -0.3 & -5.6 & $7.9 \pm 0.1$ \\
\hline & 264 & 28.7 & -0.2 & -5.9 & $9.4 \pm 0.1$ \\
\hline \multirow{6}{*}{$\begin{array}{l}\text { B4 (25 LLDPE/75 } \\
\text { waste) }\end{array}$} & 48 & 22.3 & -0.45 & -5.9 & $1.4 \pm 0.2$ \\
\hline & 72 & 21.6 & -0.05 & -6.0 & $0.8 \pm 0.2$ \\
\hline & 120 & 21.2 & -0.14 & -5.75 & $0.3 \pm 0.1$ \\
\hline & 168 & 23.6 & -0.2 & -6.20 & $2.7 \pm 0.2$ \\
\hline & 216 & 22.30 & -0.13 & -13.0 & $7.4 \pm 0.3$ \\
\hline & 264 & 21.8 & 0.3 & -6.0 & $1.1 \pm 0.1$ \\
\hline \multirow{6}{*}{$\begin{array}{l}\text { B5 (10 LLDPE/90 } \\
\text { waste) }\end{array}$} & 48 & 18.74 & 0.09 & -5.33 & $1.91 \pm 0.2$ \\
\hline & 72 & 19.26 & -0.39 & -5.94 & $2.43 \pm 0.2$ \\
\hline & 120 & 28.22 & -0.14 & -4.68 & $1.48 \pm 0.1$ \\
\hline & 168 & 26.0 & -0.2 & -4.80 & $1.11 \pm 0.1$ \\
\hline & 216 & 29.97 & 0.21 & -4.43 & $3.11 \pm 0.3$ \\
\hline & 264 & 21.94 & 0.14 & -6.56 & $5.51 \pm 0.3$ \\
\hline
\end{tabular}

of the material. It can also result in overcoming specific ageing conditions or severity of weathering parameters to eliminate the suspected propagation of surface microcracks and morphological changes in the studied formulations [55]. 


\section{Conclusions}

Compounded specimens of virgin LLDPE and plastic film waste were examined after exposure to accelerated weathering, and the mechanical and physical properties were evaluated and reported in this work. It was found that the Die Head Temperature of the extruder's blown-film technique used altered the mechanical properties based on the suspected melting homogeneity of the polymeric matrix. Addition of the waste fraction in the blend reduced Young's modulus at threshold limit by $50 \%$, and an incremental decrease was noted in other mechanical properties proportional to waste content. Minimal difference in stress and strain behaviour was noticed between the specimens compounded on a DHT of 175 and $195^{\circ} \mathrm{C}( \pm 5 \%)$. This indicated that miscibility of the polymers on a molecular level was not achieved based on the melting of the materials and their behaviour. It also indicates that, due to the presence of $\mathrm{PP}$ in the waste blend, either of those temperatures will govern the blend based on surpassing melting points of all polymers, whereas a DHT of $185^{\circ} \mathrm{C}$ does not achieve a compatibility blend. The total change in colour $(\Delta E)$ based on the evaluation of the colour parameters investigated did not show a clear trend amongst examined specimens but indicated a more change in surface chemistry of the polymers studied. The blends were also investigated for their applicability as a standalone product competing in the local market against the plastics used for indoor applications, namely, carrier bags. It was found after examining the mechanical properties of the locally used carrier bags and reviewing standards and properties found in the literature that the mechanically recycled blends present results comparable to such products. This indicates that because plastic waste in Kuwait is discarded only after a single use, it preserves its integrity for further utilization. Unfortunately, this also touches social and economic issues (beyond the scope of this work). This shows the potential these wastes hold in reducing the processing costs of plastic product converters, which can also decrease their utility demand and fresh resin costs. Depending on the nature of the intended potential use of the developed product, hygienic and health matters may also be involved if, for example, the recycled products are to be used in packaging food and consumables. The durability of the recycled blends was also examined by observing a degradation effect upon simulating an outdoor exposure, indicating the potential for using dry blended recycled products in Kuwait as plastic covers for various outdoor applications. It can also be concluded that the technique used in this work for formulating the aforementioned blends could be enhanced by adding pigments for customer satisfaction and additives for prolonging their service life.

\section{Competing Interests}

The authors declare that there is no conflict of interests regarding the publication of this paper.

\section{Acknowledgments}

The Environment and Life Sciences Research Centre (ELSRC) of the Kuwait Institute for Scientific Research (KISR), the Kuwait Foundation for the Advancement of Sciences (KFAS), and EQUATE Petrochemical Company are gratefully acknowledged for funding this research project (PC017C). The knowledge and knowhow is protected under the regulations of the Kuwait Institute for Scientific Research (KISR), namely, Marketing \& Commercialization Division. Eng. F. Husain Jassem, Mr. M. Al-Mujaibel, and A. Al-Marshad are graciously acknowledged for their support of this work. Dr. A. Tuhl (NWM Co., Kuwait) contribution is appreciated during the initial stages of this work.

\section{References}

[1] K. Rajakumar, V. Sarasvathy, A. Thamarai Chelvan, R. Chitra, and C. T. Vijayakumar, "Natural weathering studies of polypropylene," Journal of Polymers and the Environment, vol. 17, no. 3, pp. 191-202, 2009.

[2] J. Pilař, D. Michálková, M. Šlouf, and T. Vacková, "Long-term accelerated weathering of HAS stabilized PE and PP plaques: compliance of ESRI, IR, and microhardness data characterizing heterogeneity of photooxidation," Polymer Degradation \& Stability, vol. 120, pp. 114-121, 2015.

[3] A. Bhattacharyya, S. Chen, and M. Zhu, "Graphene reinforced ultra high molecular weight polyethylene with improved tensile strength and creep resistance properties," eXPRESS Polymer Letters, vol. 8, no. 2, pp. 74-84, 2014.

[4] P. Srimalanon, W. Yamsaengsung, A. Kositchaiyong, E. Wimolmala, K. Isarangkura, and N. Sombatsompop, "Effects of UVaccelerated weathering and natural weathering conditions on anti-fungal efficacy of wood/PVC composites doped with propylene glycol-based HPQM," eXPRESS Polymer Letters, vol. 8, pp. 74-84, 2014.

[5] A. Dehbi, A. Bouaza, A. Hamou, B. Youssef, and J. M. Saiter, "Ageing effect on the properties of tri-layer polyethylene film used as greenhouse roof," Materials \& Design, vol. 31, pp. 864869, 2010.

[6] M. Sánchez-Soto, A. Rossa, A. J. Sánchez, and J. GámezPérez, "Blends of HDPE wastes: study of the properties," Waste Management, vol. 28, no. 12, pp. 2565-2573, 2008.

[7] M. Liu and A. R. Horrocks, "Effect of carbon black on UV stability of LLDPE films under artificial weathering conditions," Polymer Degradation \& Stability, vol. 75, no. 3, pp. 485-499, 2002.

[8] C.-S. Li, M.-S. Zhan, X.-C. Huang, and H. Zhou, "Degradation behavior of ultra-high molecular weight polyethylene fibers under artificial accelerated weathering," Polymer Testing, vol. 31, no. 7, pp. 938-943, 2012.

[9] T. Lundin, S. M. Cramer, R. H. Falk, and C. Felton, "Accelerated weathering of natural fiber-filled polyethylene composites," Journal of Materials in Civil Engineering, vol. 16, no. 6, pp. 547$555,2004$.

[10] C. Fonseca-Valero, J. Arranz-Andrés, A. Ochoa-Mendoza, and C. González-Sánchez, "Mechanical recycling and composition effects on the properties and structure of hardwood cellulosereinforced high density polyethylene eco-composites," Composites Part A: Applied Science and Manufacturing, vol. 69, pp. 94104, 2015. 
[11] A.-H. I. Mourad, "Thermo-mechanical characteristics of thermally aged polyethylene/polypropylene blends," Materials and Design, vol. 31, no. 2, pp. 918-929, 2010.

[12] S. M. Al-Salem, "Establishing an integrated databank for plastic manufacturers and converters in Kuwait," Waste Management, vol. 29, no. 1, pp. 479-484, 2009.

[13] S. M. Al-Salem, P. Lettieri, and J. Baeyens, "The valorization of plastic solid waste (PSW) by primary to quaternary routes: from re-use to energy and chemicals," Progress in Energy \& Combustion Science, vol. 36, no. 1, pp. 103-129, 2010.

[14] A. G. Pedroso and D. S. Rosa, "Mechanical, thermal and morphological characterization of recycled LDPE/corn starch blends," Carbohydrate Polymers, vol. 59, no. 1, pp. 1-9, 2005.

[15] E. B. A. V. Pacheco, L. M. Ronchetti, and E. Masanet, "An overview of plastic recycling in Rio de Janeiro," Resources, Conservation \& Recycling, vol. 60, pp. 140-146, 2012.

[16] M. A. Salem, "Mechanical properties of UV-irradiated lowdensity polyethylene films formulated with carbon black and titanium dioxide," Egypt Journal of Soil Science, vol. 24, pp. 141150, 2001.

[17] P. A. Dilara and D. Briassoulis, "Degradation and stabilization of low-density polyethylene films used as greenhouse covering materials," Journal of Agricultural Engineering Research, vol. 76, no. 4, pp. 309-321, 2000.

[18] A. L. Andrady, H. S. Hamid, and A. Torikai, "Effects of climate change and UV-B on materials," Photochemical \& Photobiological Sciences, vol. 2, no. 1, pp. 68-72, 2003.

[19] M. A. Tuasikal, O. Y. Alothman, M. Luqman, S. M. AlZahrani, and M. Jawaid, "Influence of natural and accelerated weathering on the mechanical properties of low-density polyethylene films," International Journal of Polymer Analysis and Characterization, vol. 19, no. 3, pp. 189-203, 2014.

[20] S. M. Al-Salem, "Influence of natural and accelerated weathering on various formulations of linear low density polyethylene (LLDPE) films," Materials \& Design, vol. 30, no. 5, pp. 1729-1736, 2009.

[21] M. Philip, J. Attwood, A. Hulme, G. Williams, and P. Shipton, "Evaluation of weathering in mixed polyethylene and polypropylene products," Tech. Rep., The Waste \& Resources Action Programme (WRAP), Banbury, UK, 2004.

[22] M. Gahleitner, "A second life for polymers, needs more research," eXPRESS Polymer Letters, vol. 10, p. 187, 2016.

[23] F. P. La Mantia, "Recycling of heterogeneous plastics wastes: I-Blends with low-density polyethylene," Polymer Degradation and Stability, vol. 37, no. 2, pp. 145-148, 1992.

[24] F. P. La Mantia and D. Curto, "Recycling of degraded polyethylene: blends with nylon 6," Polymer Degradation \& Stability, vol. 36, no. 2, pp. 131-135, 1992.

[25] "Standard practice for sampling of plastics," ASTM D 1898-68, American Society for Testing and Materials, Philadelphia, Pa, USA, 1989.

[26] S. M. Al-Salem, G. Abraham, O. A. Al-Qabandi, and A. M. Dashti, "Investigating the effect of accelerated weathering on the mechanical and physical properties of high content plastic solid waste (PSW) blends with virgin linear low density polyethylene (LLDPE)," Polymer Testing, vol. 46, pp. 116-121, 2015.

[27] ASTM, "Standard test method for tensile properties of thin plastic sheeting," ASTM D 882, American Society for Testing and Materials, Philadelphia, Pa, USA, 2010.

[28] American Society for Testing and Materials (ASTM D 1003), ASTM Annual Book, PA, 2011.
[29] S. M. Al-Salem, "Influence of meteorological parameters on formulations of LLDPE exposed to natural (outdoor) weathering: statistical analysis of data obtained from physical and mechanical characterization," Journal of Environmental Resources \& Development, vol. 2, pp. 680-690, 2008.

[30] S. M. Al-Salem, G. Abraham, O. A. Al-Qabandi, and A. M. Dashti, "Dashti. Investigating the applicability of mechanical recycling in Kuwait by studying developed standardized film samples from virgin/waste polymer resins subjected to accelerated weathering," in Proceedings of the 15th Chemical Engineering and Chemical Technologies Conference, pp. 278-288, Istanbul, Turkey, December 2015.

[31] S. M. Al-Salem, "Evaluation of virgin polyolefin compounds with plastic film waste formulations degradation: product development opportunities from solid waste using varied processing conditions," in Proceedings of the 8th International HSSE \& Loss Prevention Professional Development Conference and Exhibition, American Society of Safety Engineers (ASSE), Kuwait City, Kuwait, December 2015.

[32] American Society for Testing and Materials, ASTM Annual Book, ASTM D 4329, American Society for Testing and Materials, West Conshohocken, Pa, USA, 2005.

[33] D. A. Johnson, J. L. Urich, R. M. Rowell, R. Jacobson, and D. F. Courtfield, "Weathering characteristics of fiber-polymer composites," in Proceedings of the 5th International Conference on Wood Fiber-plastic Composites, Madison, Wisc, USA, 1999.

[34] American Society for Testing and Materials, ASTM Annual Book, ASTM D 2244, ASTM, Conshohocken, Pa, USA, 2011.

[35] C. N. Kartalis, C. D. Papaspyrides, R. Pfaendner, K. Hoffmann, and H. Herbst, "Mechanical recycling of post-used HDPE crates using the restabilization technique. II: influence of artificial weathering," Journal of Applied Polymer Science, vol. 77, no. 5, pp. 1118-1127, 2000.

[36] C. N. Kartalis, C. D. Papaspyrides, R. Pfaendner, K. Hoffmann, and H. Herbst, "Mechanical recycling of postused high-density polyethylene crates using the restabilization technique. I. Influence of reprocessing," Journal of Applied Polymer Science, vol. 73, no. 9, pp. 1775-1785, 1999.

[37] C. Albano and G. Sanchez, "Study of the mechanical, thermal, and thermodegradative properties of virgin PP with recycled and non-recycled HDPE," Polymer Engineering \& Science, vol. 39, no. 8, pp. 1456-1462, 1999.

[38] D. Briassoulis, A. Aristopoulou, M. Bonora, and I. Verlodt, "Degradation characterisation of agricultural low-density polyethylene films," Biosystems Engineering, vol. 88, no. 2, pp. 131-143, 2004.

[39] A. Elzubair and J. C. Miguez Suarez, "Mechanical behavior of recycled polyethylene/piassava fiber composites," Materials Science \& Engineering A, vol. 557, pp. 29-35, 2012.

[40] I. Whitten and G. Youssef, "The effect of ultraviolet radiation on ultrasonic properties of polyurea," Polymer Degradation \& Stability, vol. 123, pp. 88-93, 2016.

[41] D. S. Bajwa, S. G. Bajwa, and G. A. Holt, "Impact of biofibers and coupling agents on the weathering characteristics of composites," Polymer Degradation and Stability, vol. 120, pp. 212-219, 2015.

[42] A. Camann, K. Dragsbaek, S. Krol, J. Sandgren, and D. Song, Properties, Recycling and Alternatives to PE Bags. An Interactive Qualifying Project Report, Worcester Polytechnic Institute, Worcester, Mass, USA, 2010.

[43] A. A. Basfar and K. M. Idriss Ali, "Natural weathering test for films of various formulations of low density polyethylene 
(LDPE) and linear low density polyethylene (LLDPE)," Polymer Degradation \& Stability, vol. 91, no. 3, pp. 437-443, 2006.

[44] H. Makki, K. N. S. Adema, M. M. R. M. Hendrix et al., "Quantitative spectroscopic analysis of weathering of polyesterurethane coatings," Polymer Degradation \& Stability, vol. 121, pp. 280-291, 2015.

[45] H. Makki, K. N. S. Adema, M. M. R. M. Hendrix et al., "Weathering of a polyester-urethane clearcoat: lateral inhomogeneities," Polymer Degradation \& Stability, vol. 122, pp. 180-186, 2015.

[46] J. R. White and A. Turnbull, "Weathering of polymers: mechanisms of degradation and stabilization, testing strategies and modelling," Journal of Materials Science, vol. 29, no. 3, pp. 584613, 1994 .

[47] L. C. Mendes, E. S. Rufino, F. O. C. de Paula, and A. C. Torres Jr., "Mechanical, thermal and microstructure evaluation of HDPE after weathering in Rio de Janeiro City," Polymer Degradation \& Stability, vol. 79, no. 3, pp. 371-383, 2003.

[48] A. Aranzabal, D. Iturbe, M. Romero-Sáez, M. P. GonzálezMarcos, J. R. González-Velasco, and J. A. González-Marcos, "Optimization of process parameters on the extrusion of honeycomb shaped monolith of H-ZSM-5 zeolite," Chemical Engineering Journal, vol. 162, no. 1, pp. 415-423, 2010.

[49] M. D. H. Beg and K. L. Pickering, "Accelerated weathering of unbleached and bleached Kraft wood fibre reinforced polypropylene composites," Polymer Degradation \& Stability, vol. 93, no. 10, pp. 1939-1946, 2008.

[50] T. Ojeda, A. Freitas, K. Birck et al., "Degradability of linear polyolefins under natural weathering," Polymer Degradation and Stability, vol. 96, no. 4, pp. 703-707, 2011.

[51] F. Habla, C. Fernandes, M. Maier et al., "Development and validation of a model for the temperature distribution in the extrusion calibration stage," Applied Thermal Engineering, vol. 100, pp. 538-552, 2016.

[52] A. Dehbi, A. I. Mourad, and A. Bouaza, "Ageing effect on the properties of tri-layer polyethylene film used as greenhouse roof," Procedia Engineering, vol. 10, pp. 466-471, 2011.

[53] S. Bejgarn, M. MacLeod, C. Bogdal, and M. Breitholtz, "Toxicity of leachate from weathering plastics: an exploratory screening study with Nitocra spinipes," Chemosphere, vol. 132, pp. 114-119, 2015.

[54] J. S. Fabiyi and A. G. McDonald, "Degradation of polypropylene in naturally and artificially weathered plastic matrix composites," Maderas: Ciencia y Tecnología, vol. 16, no. 3, pp. 275-290, 2014.

[55] J. V. Gulmine, P. R. Janissek, H. M. Heise, and L. Akcelrud, "Degradation profile of polyethylene after artificial accelerated weathering," Polymer Degradation and Stability, vol. 79, no. 3, pp. 385-397, 2003. 

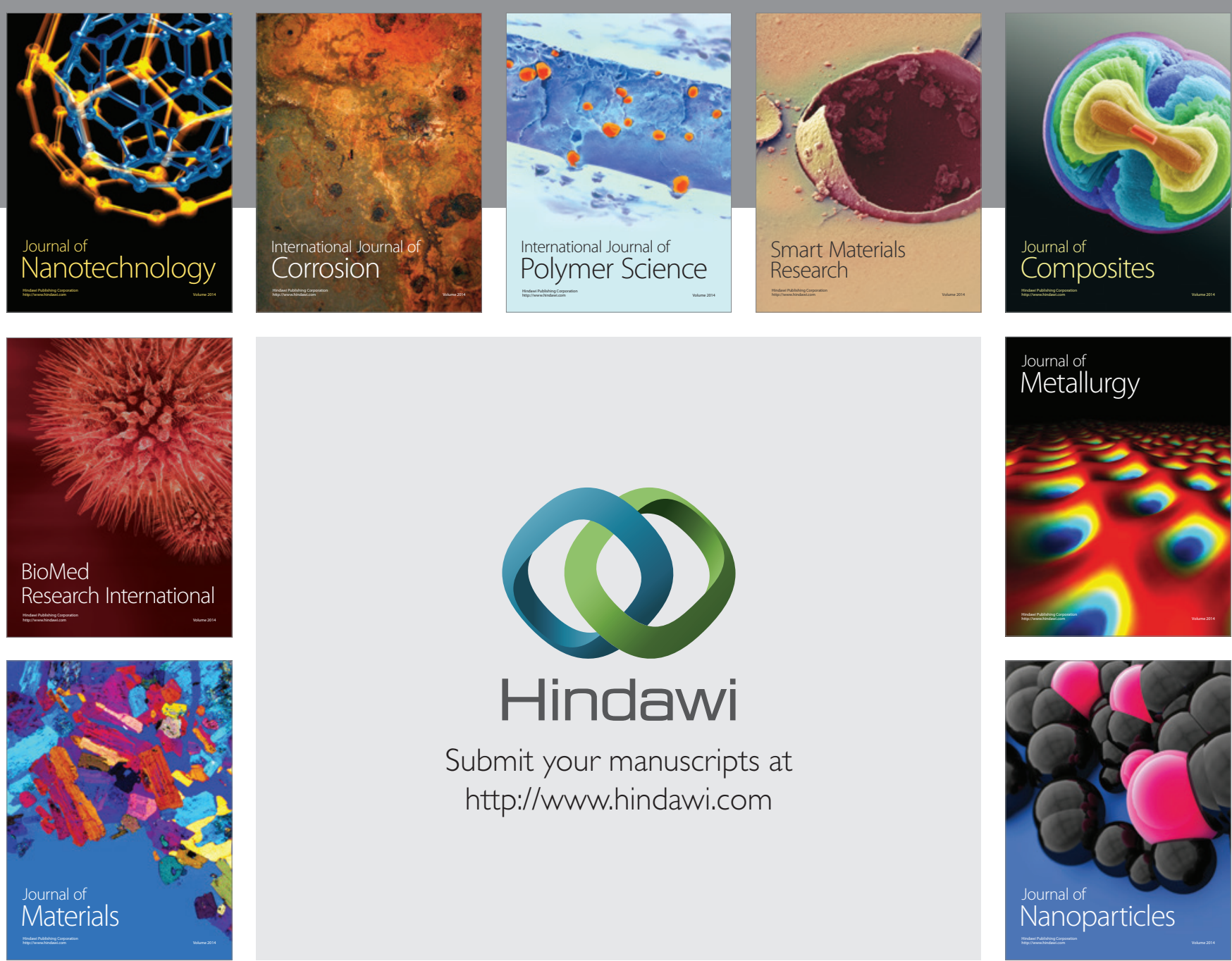

\section{Hindawi}

Submit your manuscripts at

http://www.hindawi.com

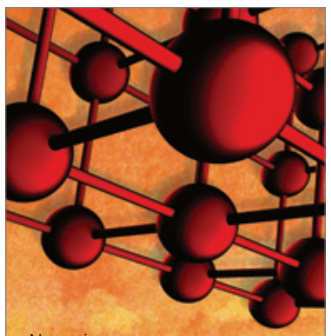

Materials Science and Engineering
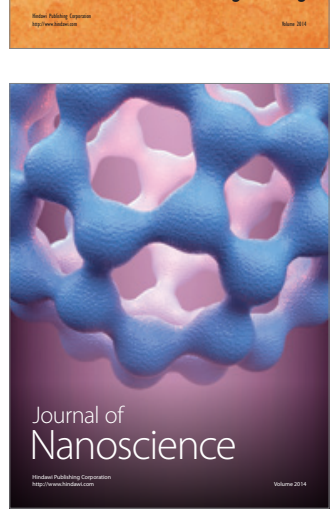
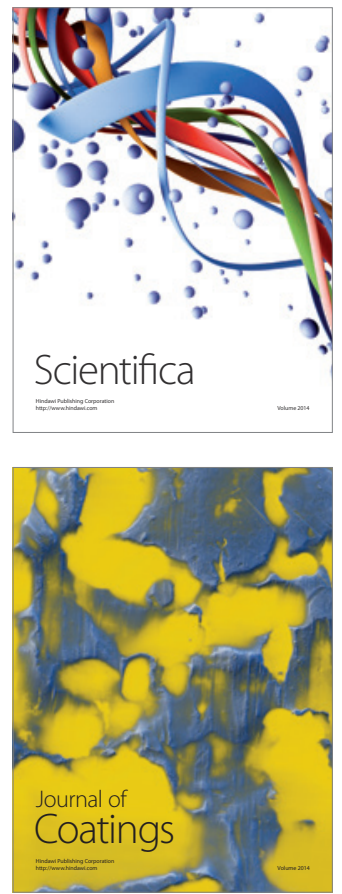
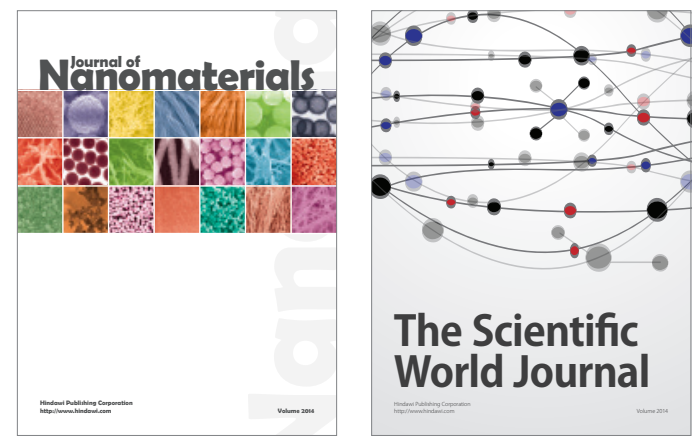

The Scientific World Journal
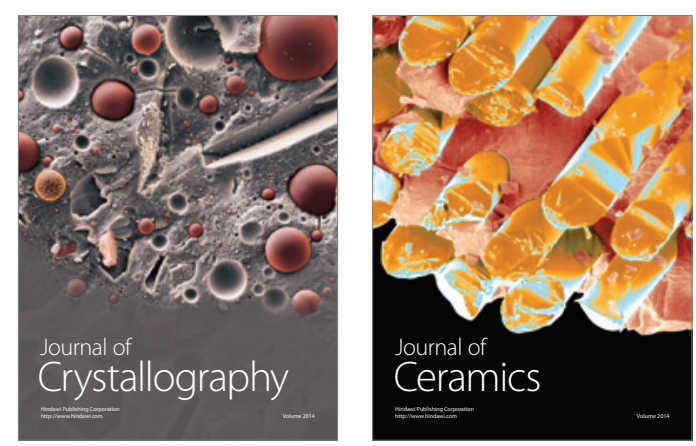
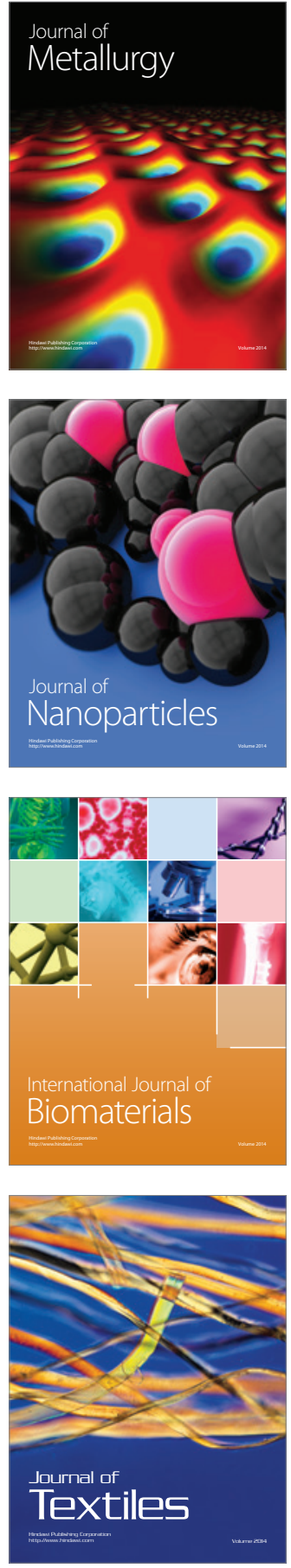